\title{
Dynamic Response Analysis of the Coal Gangue-like Elastic Rock Sphere Impact on the Massless Tail Beam Based on Contact-Structure Theory and FEM
}

\author{
Yang Yang $(\mathbb{D}$, Lirong Wan $(\mathbb{D}$, and Zhengyuan Xin \\ College of Mechanical and Electronic Engineering, Shandong University of Science and Technology, Qingdao 266590, China \\ Correspondence should be addressed to Lirong Wan; lirong.wan@sdust.edu.cn
}

Received 5 June 2019; Revised 24 August 2019; Accepted 5 September 2019; Published 27 October 2019

Academic Editor: Hassan Haddadpour

Copyright (c) 2019 Yang Yang et al. This is an open access article distributed under the Creative Commons Attribution License, which permits unrestricted use, distribution, and reproduction in any medium, provided the original work is properly cited.

\begin{abstract}
The impact and collision behavior between the coal gangue and the hydraulic support widely exists in the top coal caving. However, due to the complex interactions between the large number of coal gangue particles in the mining surface and the limitations of the coal mining technology and other factors, it becomes a difficult problem to study the collision behavior and the contact response between the coal gangue and the hydraulic support or its main components under the actual caving conditions. In order to accurately grasp the contact response law when the coal gangue impacts the tail beam of the hydraulic support, in combination with the equivalent stiffness of the tail beam jack, the Lankarani-Nikravesh (L-N) nonlinear spring-damping contact model, the structural mechanics model of the tail beam, and the energy conservation law, this paper firstly establishes the system contact-structure dynamic model when the particles impact on the tail beam based on the tail beam equivalent kinematics model. Then, to further study the system contact response, the spring damper module is used in the finite element software for the first time to replace the hydraulic cylinder, and four different types of the rigid-flexible coupling simulations when the impact heights, the impact positions, the rock radii, and the rock materials change are conducted, respectively. Through the combination of the theory and the simulation, the contact response law when the particles impacting the massless tail beam under different working conditions is obtained, and the system contact response differences as well as the coal gangue identifying feasibility on the basis of the response differences after the coal gangue impact are analyzed. The conclusions will provide theoretical reference and simulation method for the study of the impact-contact behavior between the coal gangue and the hydraulic support.
\end{abstract}

\section{Introduction}

China is a country with coal as its primary resource [1-5]. China's economy has entered a new normal [6] since the 13th Five-Year Plan was implemented and the coal output has slowed down. However, from the coal production of China from 2008 to 2018 in Figure 1 [7-17], China's raw coal output still reached 3.68 billion tons in 2018, and the total mined production of the coal remains very large. Meanwhile, according to China's primary energy consumption structure prognostic figure Figure $2[6,18]$, coal proportion by 2030 will continue to account for more than 60 percent, and it will maintain its dominant position that is irreplaceable for a long time. Moreover, as the important technology of coal mining and the key technology of thick coal seam mining, the study of the top coal caving technology [19-22] is of great significance to improve the mining efficiency and realize the digital mine construction.

As the important mining method, the top coal caving technology and its correlation technique have been studied by plenty of scholars. Yu et al. [23, 24] investigated the fracturing and caving of overburden, put forward the statistical formula of the failure zone maximum heights in the longwall top coal caving (LTCC), and studied the overburden fracturing by the microseismic monitoring. Cao et al. [25] studied the microseismicity in the LTCC through the Flac $^{3 \mathrm{~d}}$ numerical modelling. In the mine which is mining through the combination of a fully mechanized traditional longwall and LTCC methods, Basarir et al. [26] researched the stress of the main and tail gates by the three-dimensional 


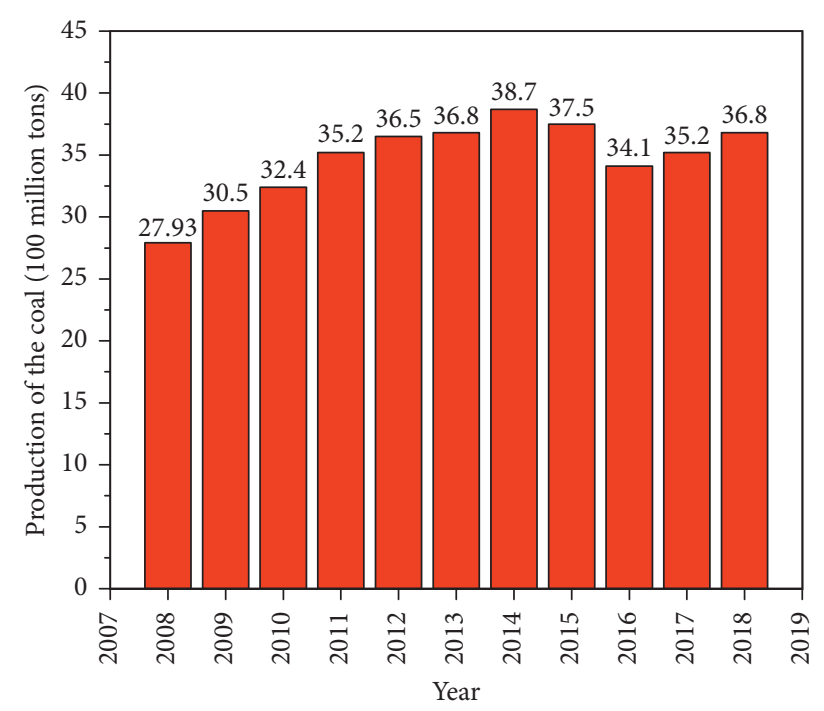

Figure 1: Energy production of China.

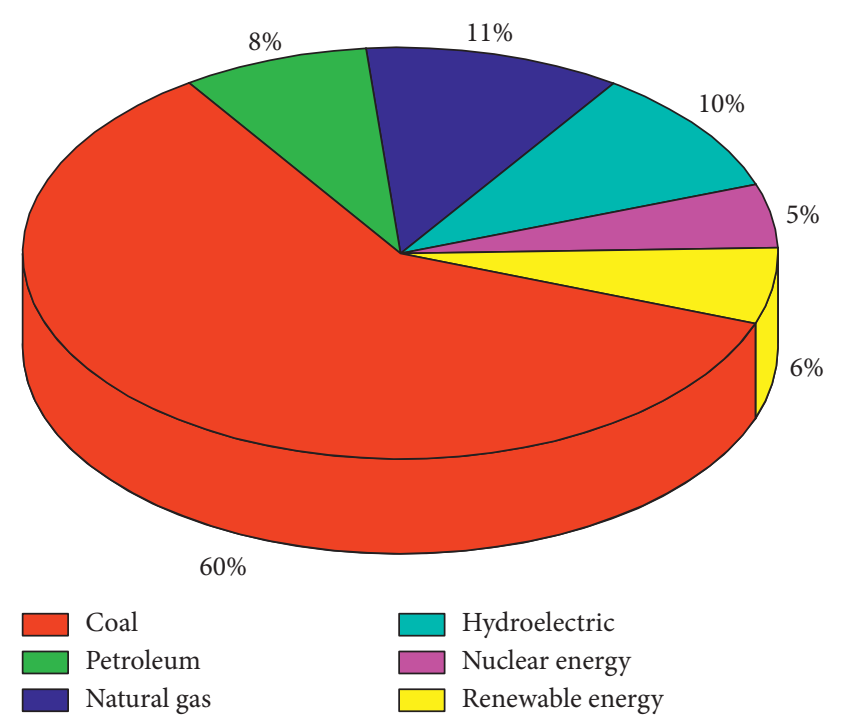

FIGURE 2: Energy consumption structure of China in 2030.

finite difference technique. Based on the in situ conditions in the top coal caving, Alehossein and Poulsen [27] provided a yield and caveability criterion. Zhang et al. [28] investigated the roof failure characteristics, forces acting on supports, and action characteristics of abutment stress of a LTCC working face. Zhang et al. [29] studied the flow of top coal and roof rock and analyzed the loss of top coal in fully mechanized top coal caving mining of extra thick coal seams. Zhang et al. [30] investigated on the coal drawing from thick steep seam with LTCC mining. Liu et al. [31] researched the roof strata conditions, shield pressure, and ground surface subsidence at a LTCC Working Face. Khanal et al. [32] using COSFLOW conducted the mine-scale analysis of LTCC. Si et al. $[33,34]$ measured the seam gas pressure, gas composition, and ventilation environment in the multilevel LTCC of ultrathick coal seams, and in order to model the gas emissions around the LTCC panels, they established a twoway sequential coupling of a geomechanical and a reservoir simulator. These studies have provided the research basis for the analysis of the mining characteristics of the top coal caving and for the development of the top coal caving technology; however, they rarely refer to the study of the impact behavior and the interaction problem between coal gangue particles and the hydraulic support in the process of top coal caving. The contact response caused by the action of coal gangue particles on the hydraulic support has also not been further explored.

The collision and contact behavior between the coal gangue particles and the hydraulic support in the top coal caving process will trigger the vibration of the hydraulic support and the disorderly collision in the coal gangue rebound process, which is of great significance to clearly understand the dynamic behavior of the hydraulic support in the application process and the coal gangue interface identification in the top coal caving process. However, the structure of the hydraulic support is complex, and the repeated impact and mutual disturbance of particles exist in the process of coal gangue particles impacting the hydraulic support, which increases the difficulty of studying the collision behavior between coal gangue particles and the hydraulic support. Therefore, as the main coal drawing component of the top coal caving hydraulic support (as shown in Figure 3), the tail beam is taken as the research object in this paper to study the contact response when the single coal gangue impacts the tail beam, so as to pave the way for the later study on the impact and collision behavior between coal gangue particles and the hydraulic support.

During the collision process between coal gangue and the tail beam, the contact behavior between particles and the tail beam will lead to the complex interlocking responses such as the compression deformation of the particle and the tail beam metal plate, the compression of the liquid within the tail beam jack under the force, and the rotation of the tail beam. Brake proposed an analytical elastic-plastic contact model in the normal direction between two round surfaces in 2012 [35], and then, he developed a new contact model for the normal and oblique impacts with the consideration of strain hardening and frictional effects [36]. Minamoto and Kawamura [37] studied the direct central impact of two identical spheres in the higher speed range. To derive forcedisplacement relations, Olsson and Larsson [38] studied the tangential contact between an elastic-plastic sphere and a rigid plane analytically and numerically. Wang et al. [39] presented a point contact model of a rigid ball and an elasticcoated solid. Rojek et al. [40] investigated the contact model for the normal interaction between elastoplastic spherical discrete elements. Jackson et al. [41] presented a different methodology for modeling the impact between elastoplastic spheres and compared the several different predicted models. Yang et al. [42, 43] studied the vertical elastic impact dynamic response between the spherical rock and the metal plate and the vertical impact-contact response between the elastic sphere and elastic half space. Wang et al. [44] established a new nonlinear hysteretic model with considering the loading, unloading, and reloading processes. Yan et al. [45] investigated the influence of the falling rock's shape and impact poses on the impact force and response of 


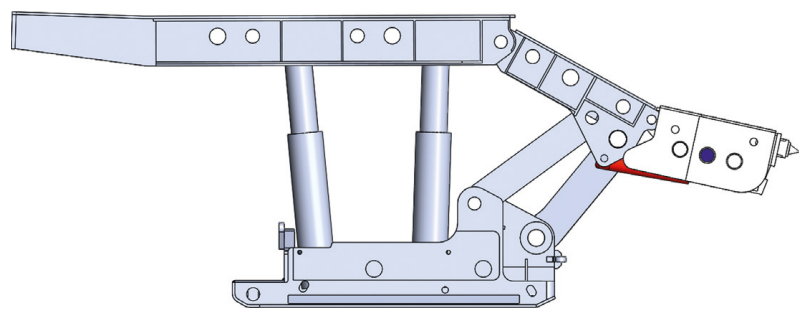

FIgURE 3: Hydraulic support in longwall top coal caving.

RC slabs. Skrinjar et al. [46] compared the evolution of the contact force during the contact process for the general contact-force models and the cylindrical contact-force models. Willert et al. [47] studied the influence of the Tabor parameter on the spheres adhesive normal impact. Zhao et al. [48] investigated the contact problem between the power-law hardening elastic-plastic sphere and the rigid flat under the combination of the normal and tangential loads. Wang et al. [49] conducted the research about the interparticle contact behaviors and microcontact models. Lu et al. [50] studied the contact behavior between the rigid flat and the coated asperity. Yuan et al. [51] established the mechanical model of contact between a sphere-based fractal rough surface and a rigid flat surface. Wang et al. [52] analyzed the mechanical response mechanism when the rockfall impacted the soil cushion layer. Indeed, these research studies on the contact problem or the rock impact problem provided the basic theoretical models, the numerical simulation methods, and the references for the study of impact-contact behavior between coal gangue particles and the tail beam. But they have only referred to the contact behavior between spheres and between the sphere and the plane, or the study of the collision between the sphere and the soil mass. Impact-contact systems are simple. The compression of the liquid under the force and the force transfer of multibody composite structure are not involved. Liang et al. [53] and Wan et al. [54] studied the response when the hydraulic-powered support supported the impacting load; however, they just added the self-defined force on the hydraulic support, the impact and contact process between the coal gangue and the hydraulic support was ignored, and the contact theory when the coal gangue impacts the hydraulic support has not been established yet.

On the basis of the previous research results and research deficiencies, to clarify the contact response law of the system after the impact of coal gangue particles on the tail beam of the hydraulic support and grasp the response difference of the system when the coal gangue particles impact the tail beam, respectively, based on the L-N contact model, the kinematics model of the tail beam device, the rotational model of the tail beam impacted by coal gangue particles, and the mechanical model of the tail beam impacted by coal gangue particles is constructed. Then, combining with the contact mechanics and structural mechanics, the dynamic model of the coal gangue particles impacting the tail beam is finally established. Besides, the tail beam owns large volume and mass while the selected particles produced slight impact-contact force. In order to accurately obtain the response of the tail beam under the contact force produced by the impact of the coal gangue particles, the gravity of the tail beam is not considered in this paper. On this basis, the spring damper module is used to replace the hydraulic cylinder in the finite element software for the first time, and then, the finite element simulation model of the coal gangue particles elastic impact on the massless tail beam is constructed. Different types of dynamics simulation of finite element contact are carried out, and the effects of the impact height, the impact position, the rock radii, and the material properties on the system contact response are analyzed.

The remainder of the paper is organized as follows: Section 2 establishes the kinematics model of the tail beam device. Section 3 constructs the rotational model and the mechanical model of the tail beam impacted by coal gangue particles and finally establishes the dynamic model of the coal gangue particles impacting the tail beam. Section 4 introduces the establishing process of the simulation model, the simulation settings, and the simulation types. Section 5 analyzes the influence of the impact height, the impact position, the rock radii, and the material properties on the system contact response. Section 6 shows some related work and our conclusion.

\section{Kinematics Model of the Tail Beam Device}

In this project, the tail beam of hydraulic support is counted as the research object. The supporting effect of the shield beam and other components of the hydraulic support on the tail beam is equivalent to that of the rigid support frame. As a result, as shown in Figure 4, a simplified model of the tail beam device as well as a two-dimensional simplified rod diagram of the tail beam can be obtained (the unit of the length in Figure 4 is $\mathrm{mm}$ ).

The size of the tail beam remains constant during the movement process. After the simplification of Figure 4, the kinematics diagram of the tail beam (see Figure 5) can be obtained. And if A-B-F-G-H is taken as the vector ring, the equation of closed-loop can be expressed as follows:

$$
\overrightarrow{A B}+\overrightarrow{B F}=\overrightarrow{A H}+\overrightarrow{H G}+\overrightarrow{G F}
$$

It is assumed that the angle between $\mathrm{AB}$ ( $\mathrm{A}$ is the center point of the hinged joint hole between the tail beam and shield beam; B is the center point of the hinged joint hole between the tail beam and the jack) is $\theta$. The effective length of the liquid column $\mathrm{HG}$ is $s$ (variate). The angle $\angle \mathrm{ABF}$ is assumed to be $\alpha$, the angle between the jack and the horizontal direction is $\beta$, and the angle between the upper surface of the tail beam CD and the horizontal direction is $\xi$. It can be obtained as follows:

$$
\left\{\begin{array}{l}
A B \cdot \cos \theta+B F \cdot \cos (\pi-\alpha-\beta-\theta)=(A H+H G+G F) \cdot \cos \beta, \\
B F \cdot \sin (\pi-\alpha-\beta-\theta)-A B \cdot \sin \theta=(A H+H G+G F) \cdot \sin \beta .
\end{array}\right.
$$




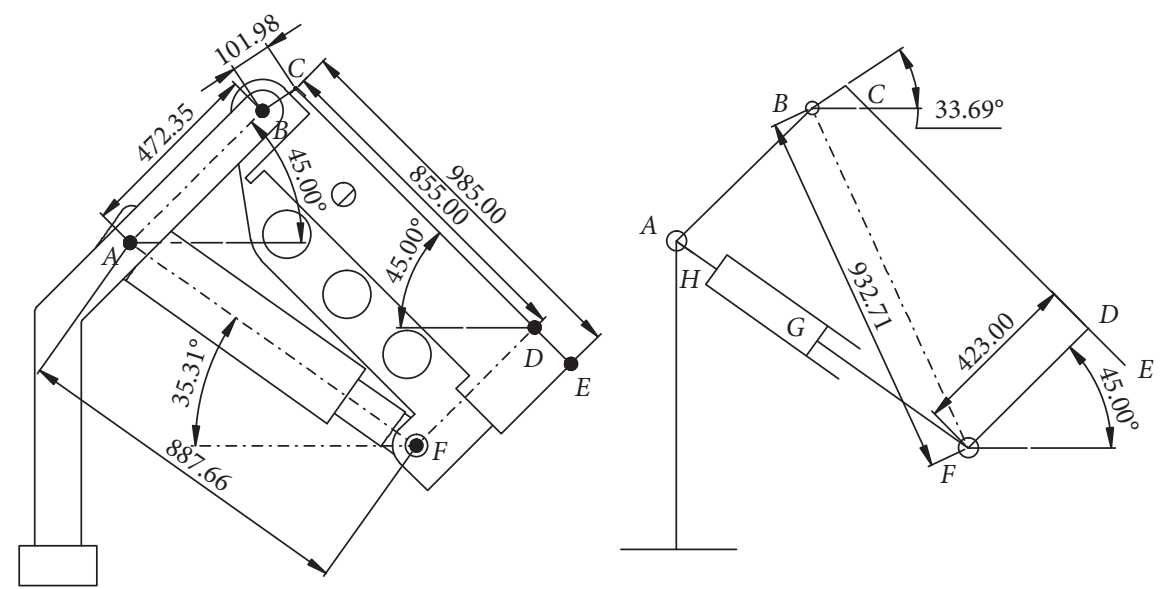

Figure 4: Diagram of the tail beam.

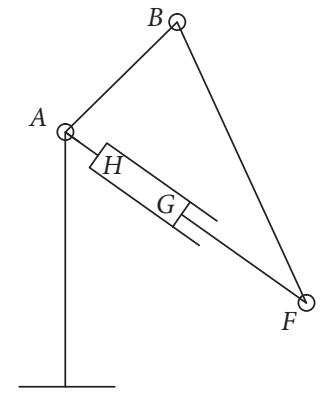

FIGURE 5: Kinematics diagram of the tail beam.

\section{Dynamic Model of the Coal Gangue Particles Impacting the Tail Beam}

3.1. Force Analysis of the Model. As shown in Figure 6(a), the tail beam and its jack reach its equilibrium state. It is assumed that the equivalent stiffness of the jack of tail beam is $K_{Q}$ after reaching the equilibrium state and the angle between the jack and the horizontal direction is $\beta_{1}$. Then, in accordance with the equivalent stiffness calculating formula [55] of the tail beam, it can be expressed as follows:

$$
K_{Q}=\frac{k_{q} \times k_{g}}{k_{q}+k_{g}}=\frac{2 S \varepsilon E_{g}}{S+2 L k_{y} \varepsilon E_{g}},
$$

where $k_{q}$ is the stiffness of the hydraulic oil (high pressure emulsion) inside the jack of the tail beam and $k_{g}$ is the stiffness of the jack cylinder. $S$ is the effective bearing area of the emulsion, $\varepsilon$ and $E_{g}$ are the thickness and elastic modulus of the cylinder, respectively. $L$ is the height of liquid column of hydraulic oil inside the jack of the tail beam, and $k_{y}$ is the volume compression coefficient of the hydraulic oil:

$$
K_{Q}=\frac{2 S \varepsilon E_{g} E_{p}}{S E_{p}+2 L \varepsilon E_{g}}
$$

where $E_{p}$ is the volume elastic modulus of the hydraulic oil and $E_{p}=\left(1 / k_{y}\right)$.
During the impact of coal gangue particles on the tail beam, a great contact force will be produced by the contact behavior. As a result, it will lead to some changes such as the compression deformation of the coal gangue particles, the deformation of the metal plate subjected to the impact, the elastic compression of the hydraulic oil in the jack of the tail beam, and the downward rotation of the tail beam around hinge point $C$ (see Figure 6(b)). In order to simplify the analysis, the change of the equivalent stiffness of the jack caused by the gravity of tail beam is ignored, as well as the change of jack stiffness during the impact of the coal gangue particles on the tail beam. In addition, the deformation of the metal plate subjected to the impact, the cross slip of particles along the metal plate in the process of coal gangue particles contacting with the metal plate is also neglected.

Based on the nonlinear relationship between contact force $\mathrm{P}$ and compression deformation $\delta \delta$, Hertz established the contact theory of sphere in contact with other objects [56-60]:

$$
\begin{aligned}
P & =K \cdot \delta \delta^{n}, \\
K & =\frac{4 \sqrt{R}}{3} \cdot E, \\
\frac{1}{E} & =\frac{1-\mu_{1}^{2}}{E_{1}}+\frac{1-\mu_{2}^{2}}{E_{2}}, \\
\frac{1}{R} & =\frac{1}{R_{1}}+\frac{1}{R_{2}}, \\
p(r) & =\frac{3 P}{2 \pi a^{2}}\left[1-\left(\frac{r}{a}\right)^{2}\right]^{1 / 2}, \\
a^{2} & =R \cdot \delta \delta,
\end{aligned}
$$

where $n$ is the nonlinear coefficient, $n=(3 / 2) . E_{1}, \mu_{1}, E_{2}$, and $\mu_{2}$ are the elastic modulus and the Poisson's ratio of two contact objects, respectively. $E$ is the equivalent elastic modulus, $R$ is the equivalent contact radius, $E$ is the contact 


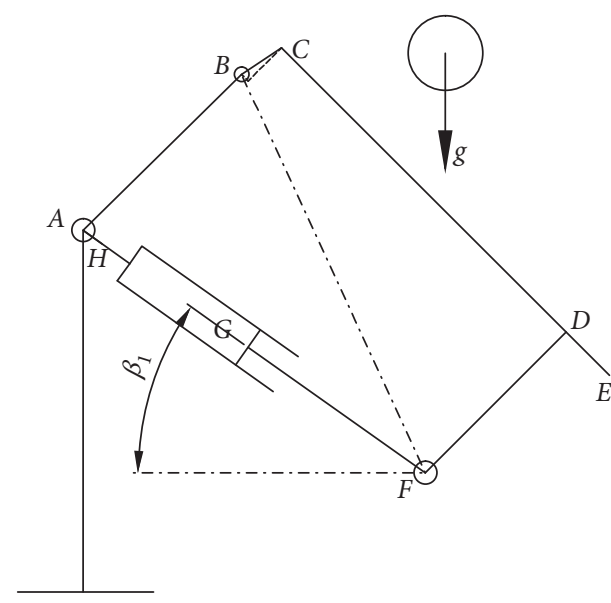

(a)

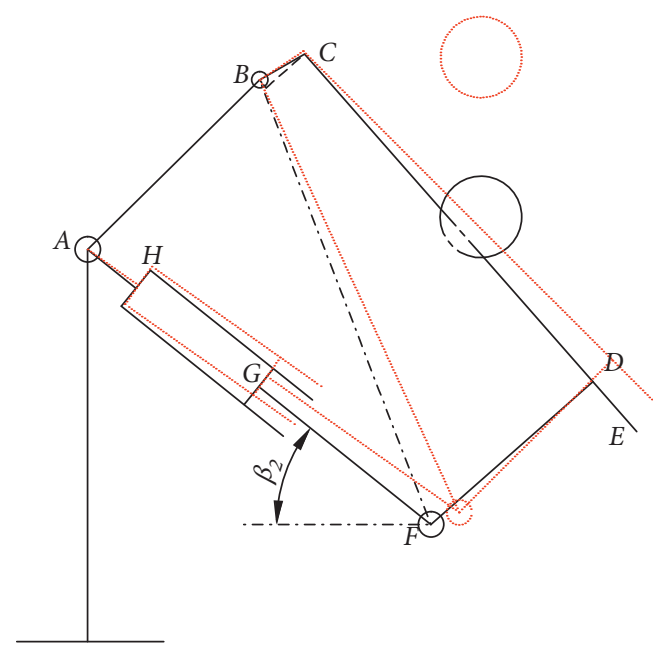

(b)

Figure 6: Process of coal gangue particles impacting the tail beam. (a) Before the impact. (b) Critical end state of shock compression.

stiffness, and $p(r)$ is the contact stress of the contact point. $a$ is the radius of the contact zone. $r$ is the distance between the contact center and the contact point. $\delta \delta$ is the compression of the sphere. $R_{1}$ and $R_{2}$ are the contact radii of two contact objects, respectively, and $R=R_{1}$ for the situation that the sphere impacting the plate.

Hertz contact theory ignores the damping force caused by the material damping and the effect of the energy losses of damping on the system contact process, which only applies to the ideal elastic contact conditions. On the basis of Hertz theory, Lankarani and Nikravesh $[61,62]$ improved the definition of the contact force and established the nonlinear spring-damping contact force models which include the Hertz ideal contact force and the dissipative force of damping. The model can be expressed as [63-67]

$$
\begin{aligned}
P & =K \cdot \delta \delta^{n}+K \cdot \delta \delta^{n} \cdot D_{n} \cdot \delta \delta, \\
D_{n} & =\frac{3\left(1-e^{2}\right)}{4 \delta \dot{\delta}_{0}},
\end{aligned}
$$

where $D_{n}$ is the damping coefficient, $\delta \delta_{0}$ is the initial velocity of elastic sphere, $\delta \delta$ is the velocity of sphere, and $e$ is the restitution coefficient.

The L-N contact model is one of the most popular and straightforward contact force models, which well conforms with experimental results. It is appropriate for analyzing the contact process of coal gangue particles impacting the metal plate of the tail beam. Therefore, this paper chooses the L-N contact model to calculate the contact force.

\subsection{Rotational Model of the Tail Beam Impacted by Coal} Gangue Particles. The tail beam is rotated downward to the limit position after the impact of coal gangue particles. Then, the rotation angle is defined as $\gamma$ and the length of the effective liquid column inside the jack before and after the rotation of the tail beam is defined as $\mathrm{HG}_{1}$ and $\mathrm{HG}_{2}$, respectively. $A F$ is changed from $A F_{1}$ to $A F_{2}$ in the rotation process, and the angle between the jack and the horizontal direction is changed to $\beta_{2}$.

$$
\left\{\begin{array}{l}
A B \cdot \cos \theta+B F \cdot \cos \left[\pi-(\alpha-\gamma)-\left(\beta_{2}+\theta\right)\right]=\left(A H+H G_{2}+G F\right) \cdot \cos \beta_{2}, \\
B F \cdot \sin \left[\pi-(\alpha-\gamma)-\left(\beta_{2}+\theta\right)\right]-A B \cdot \sin \theta=\left(A H+H G_{2}+G F\right) \cdot \sin \beta_{2} .
\end{array}\right.
$$

As is shown in Figure 7, the triangle ABF, whose side length $A F$ changes, is taken as the research object. It can be obtained according to Figure 6 and the variation conditions that 


$$
\begin{aligned}
A F_{1} & =\sqrt{(A B-B F \cdot \cos \alpha)^{2}+(B F \cdot \sin \alpha)^{2}}, \\
A F_{2} & =\sqrt{[A B-B F \cdot \cos (\alpha-\gamma)]^{2}+[B F \cdot \sin (\alpha-\gamma)]^{2}}, \\
\Delta s & =A F_{1}-A F_{2}=H G_{1}-H G_{2}, \\
\beta_{2} & =\arctan \frac{B F \cdot \sin (\alpha-\gamma)}{A B-B F \cdot \cos (\alpha-\gamma)}-\theta .
\end{aligned}
$$

3.3. Mechanical Model of the Tail Beam Impacted by Coal Gangue Particles. The tail beam is rotated downward to the limit position after the impact of coal gangue particles, which achieve a force balance under the actions of shield beam and the jack of tail beam (as is shown in Figure 8). The equilibrium equation of tail beam dynamics is obtained:

$$
\left\{\begin{array}{l}
F_{A B x}=F_{C o n} \cdot \sin \left(\frac{\pi}{2}-\xi-\gamma\right)+m g+F_{A F} \cdot \sin \beta_{2}, \\
F_{C o n} \cdot \cos \left(\frac{\pi}{2}-\xi-\gamma\right)-F_{A B y}=F_{A F} \cdot \cos \beta_{2}, \\
\sum M_{B F}=F_{A F} \cdot \cos \left(\frac{\pi}{2}-\theta-\beta_{2}\right) \cdot B F^{\prime}+F_{A F} \\
\cdot \sin \left(\frac{\pi}{2}-\theta-\beta_{2}\right) \cdot B B^{\prime}, \\
\sum M_{B Q}=-\left[F_{C o n} \cdot \sin \left(\frac{\pi}{2}-\psi\right)+m g \cdot \sin \left(\frac{\pi}{2}-\xi-\gamma+\psi\right)\right] \\
\cdot \Gamma-m g \cdot(R-\delta) \cdot \cos (\xi+\gamma), \\
\sum M_{B F}+\sum M_{B Q}=0, \\
B F^{\prime}=A B-B F \cdot \cos (\alpha-\gamma) \\
B B^{\prime}=B F \cdot \sin \varphi, \\
F_{A F}=2 K_{Q} \cdot \Delta s,
\end{array}\right.
$$

where $\delta$ is the maximum compression of the particles when coal gangue particles show vertical impact on the metal plate and lead the tail beam rotates downward to the limit position. $F_{C o n}$ is the maximum contact force between coal gangue particles and the metal plate.

3.4. Dynamic Model of the Coal Gangue Particles Impacting the Tail Beam. As shown in Figure 9, according to equations (6) and (7), the contact force generated in the contact and compression processes between the rock sphere and the tail beam during the impact is as follows:

$$
F_{\text {Con }}=K \cdot \delta^{(3 / 2)} \cdot\left(1+D_{n} \cdot \dot{\delta}\right) .
$$

The jack of the tail beam is replaced by an equivalent spring with the same stiffness, so the changes of mass center and gravitational potential energy during the compression process of the jack can be ignored. It is defined that the height between the initial position where coal gangue particles fall freely from and the position where coal gangue particles initially contact with the upper surface of the tail beam and is $h$, and the velocity of the particles in the initial contact is as follows:

$$
\begin{gathered}
v=\sqrt{2 g h}, \\
v \perp=\sqrt{2 g h} \cdot \sin \xi .
\end{gathered}
$$

When the rock sphere impacts the tail beam and is compressed, the change of its potential energy is obtained:

$$
\begin{aligned}
E_{C S}= & m g \cdot\{R \cdot \cos \xi-\Gamma \cdot \cos (\xi-\psi)-[R \cdot \cos (\xi+\gamma)-\Gamma \\
& \cdot \cos (\xi+\gamma-\psi)]+\delta \cdot \cos (\xi+\gamma)\} .
\end{aligned}
$$

According to the law of energy conservation of the system,

$$
\frac{1}{2} m \cdot v_{\perp}^{2}+E_{C S}=\int_{0}^{\delta} F_{\text {Con }} d \delta+2 \cdot \frac{1}{2} K_{Q} \cdot \Delta s^{2} .
$$

On the basis of equations (4), (8), (10), (11), (13), (14), and (15), the system contact response when the rock sphere impacting the tail beam is closely related to various parameters, such as the mass and properties of the impact object, the impact height, the contact position, and the initial position of the tail beam.

\section{Dynamic Simulation of the Impact of the Coal Gangue Particles on the Tail Beam}

To study the system contact response when the tail beam is impacted by the coal gangue particles deeply, ABAQUS software will be used to analyze the dynamic simulation of the coal gangue particles impacting the tail beam based on the kinematics and dynamics models of the coal gangue particle impacting the tail beam mentioned above.

4.1. Simulation Model and Its Mesh Generation. The 3D model of the coal gangue particles impacting the tail beam of the hydraulic support is established in Solidworks. In order to achieve a qualitative analysis, coal gangue 


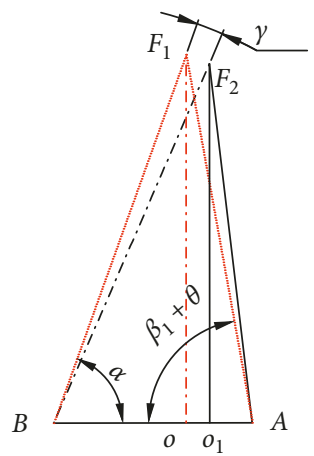

Figure 7: Movement triangle.
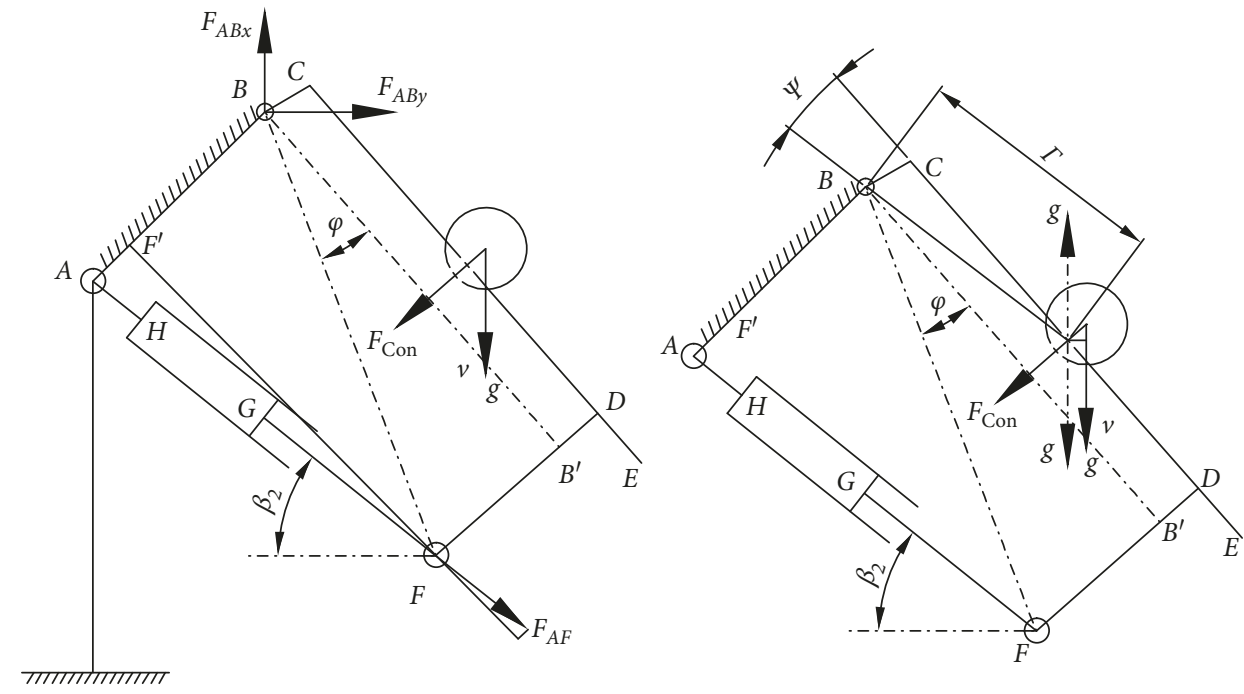

Figure 8: Mechanical model of the tail beam impacted by coal gangue particles (limit position).

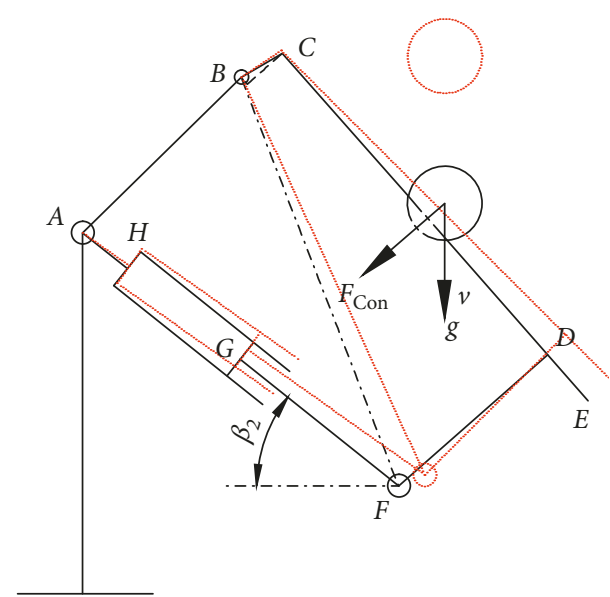

FIgURe 9: Dynamic model of the system.

particles are equivalent to elastic spheres, and the radius of particles in the simulation is $25 \mathrm{~mm}$ other than the variable radius simulation. The rock sphere owns small mass than that of the heavy hydraulic support. As a result, the impact response of the whole hydraulic support caused by the impact-contact force of the sphere and the tail beam is small. So the gravity of the tail beam is ignored to amplify the impact-contact response. At the same time, during the establishment of the dynamic model of the coal gangue particles impacting the tail beam, the influences of the top beam, shield beam, front and rear connecting rods, the base, and insert plate are not considered. According to Figure 4, the tail beam device is equivalent to the structural components where a tail beam sustained by the supporting frame. While the supporting frame supporting the tail beam replaces the shield beam and other components, the dip angle of the tail beam is not changed. And the hydraulic oil inside the jack of the tail beam exerts a great influence on the system response. However, the complexity and difficulty of the liquid simulation in ABAQUS software are high. So the jack and the hydraulic oil are replaced by the spring with the same stiffness. During the modeling process, only the terminus of the hydraulic rod of the jack and the bottom of the hydraulic cylinder is retained so as to arrange the spring, as shown in Figure 10. In order to shorten the simulation time, the free falling process of the rock sphere is not covered. And a tiny gap is reserved between the rock sphere and the metal plate in overlying strata of the tail beam during the modeling process. By applying an initial vertical velocity to the rock sphere which is similar to the initial contact velocity of the 

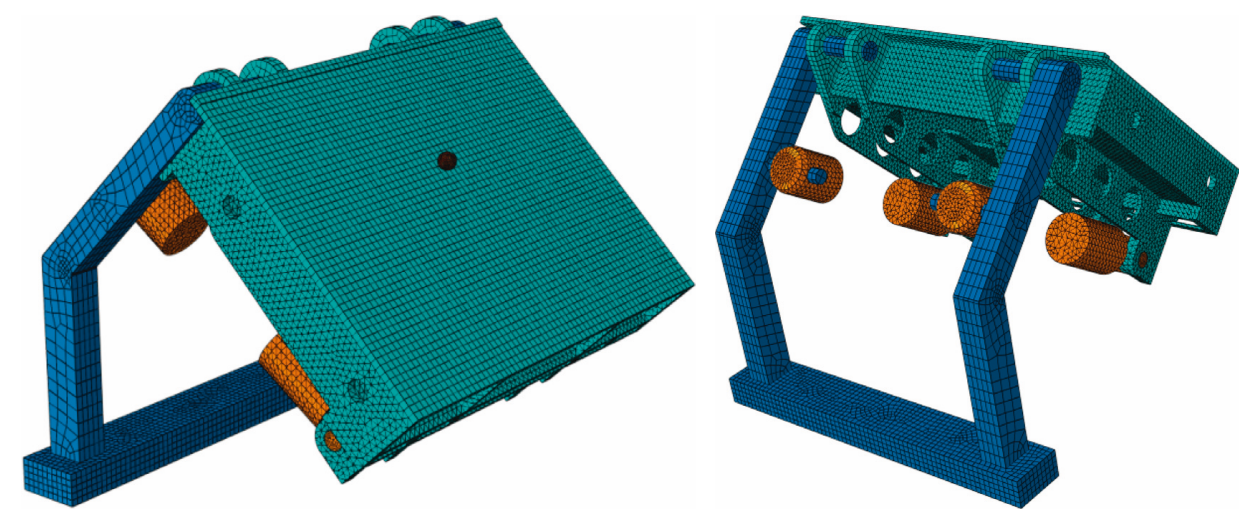

Figure 10: Simulation model after meshed.

sphere obtained from the free falling, the free falling process of the rock sphere is compensated.

The 3D model of the coal gangue particles impacting the tail beam is introduced into ABAQUS and is meshed. The rock sphere is freely meshed by means of the mesh generation function of ABAQUS. The mesh size is $0.005 \mathrm{~m}$, totaling 3,701 meshes. Hexahedral mesh can promote the calculation accuracy. However, the size of the tail beam is large and the structure of the box body is complicated. If all the tail beams are divided into hexahedral meshes, the calculation time will be greatly increased. Therefore, the metal plate of the overlying strata of tail beam (will be impacted and contacted by the rock sphere) is divided into a hexahedral mesh, as well as the connecting position between the tail beam and the support frame. And the rest is meshed freely into the tetrahedral meshes. Firstly, the tail beam will be cut by using the partition function of the software, while the metal plate of the overlying strata of the tail beam and the connecting position between the tail beam and the supporting frame is cut into standard shapes. And they will be divided into hexahedral meshes with a mesh size of $0.02 \mathrm{~m}$ while the rest of the tail beam is a tetrahedral mesh with a size of $0.02 \mathrm{~m}$. After the completion of the mesh generation, the tail beam has a total of 58,842 meshes. The supporting frame is featured by a simple structure and is cut into several standard shape bodies. Then, it will be divided into a hexahedral mesh with a size of $0.02 \mathrm{~m}$, totaling 6,263 meshes. Furthermore, an equivalent spring will be added between the terminus of the hydraulic rod of the jack and the bottom of the hydraulic cylinder. In order to reduce the coupling calculation difficulties of the finite element mesh calculation and equivalent spring force, they are meshed freely into tetrahedral meshes and the mesh size is $0.02 \mathrm{~m}$. After the completion of the mesh generation, the bottom of the hydraulic cylinder has 4,118 meshes while the terminus of hydraulic rod has 6,545 meshes. The pin of the joint between the terminus of the hydraulic rod and the tail beam is divided by the automatic division method, and the mesh size is $0.005 \mathrm{~m}$, with a total of 1566 meshes.

4.2. Settings for Contact Response and Equivalent Spring. During the impact behavior of the coal gangue particles on the tail beam, the spherical surface will be in contact with the metal plate of the overlaying strata of the tail beam, thereby causing relative movement between connectors. Therefore, the surface contact between the sphere and the metal plate of the overlaying strata of the tail beam is set. To ensure the effect of force transmission, the meshes close to the hole and the hinge pin connected to the axle hole are set as rigid elements. In the later stage of exacting the data such as the velocity and acceleration of the tail beam, to ensure the data are not affected by the vibration of the meshes itself, the velocity and acceleration data of the rigid node (near the hinged hole connected with the jack of the tail beam) at the rear side of the tail beam are selected to analyze. The position of the selected node is shown in Figure 11.

Under the flexible supporting of the jack (which is equivalently replaced by the spring in the simulation process), a relative rotation between the tail beam and other parts will occur after impact. Therefore, rotating pairs are added to the parts connected with the axle and the hole (between the tail beam and the supporting frame, between the terminus of the hydraulic rod of the jack and the supporting frame, and between the bottom of the hydraulic cylinder of the jack and the tail beam). The boundary condition is applied to the lower end-plate of the supporting frame, in which the constraint type is full constraint, and the constraint position is shown in Figure 12(a). The gravity of the tail beam itself is larger while the volume and mass of the rock sphere are smaller. Therefore, when the gravity acceleration of $-9.8 \mathrm{~m} / \mathrm{s}^{2}$ is applied to the rock sphere, the magnitude of contact force is limited. If the jack compression caused by the gravity of the tail beam is considered, the response amplitude of the tail beam and the spring will be weakened under the contact force between the rock and the tail beam. This paper aims to study the system contact and vibration response caused by the impact of coal-rock particles on the tail beam. Therefore, the gravity of the tail beam is ignored, and the gravity acceleration is also not added.

In the process of modeling, the spring is proposed to be utilized to simulate the deformation and force transmission of the jack when it is impacted. Virtual spring is used and connected at the center point between the terminus of the hydraulic rod and the bottom of the hydraulic cylinder, as shown in Figure 12(b). Moreover, parameters of the spring such as the equivalent stiffness and damping 


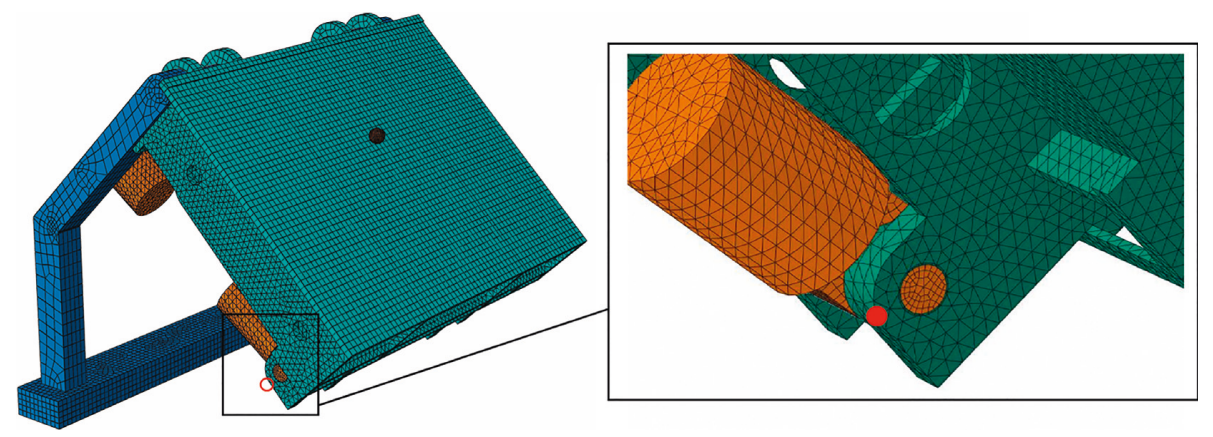

FIgURE 11: Position of the selected rigid node on the tail beam.

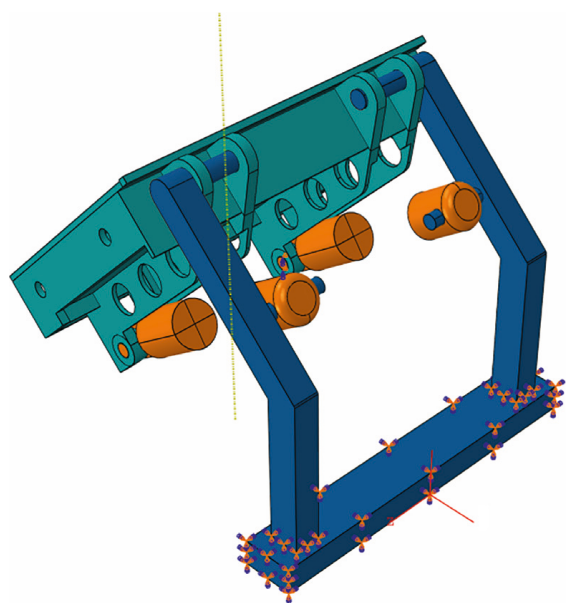

(a)

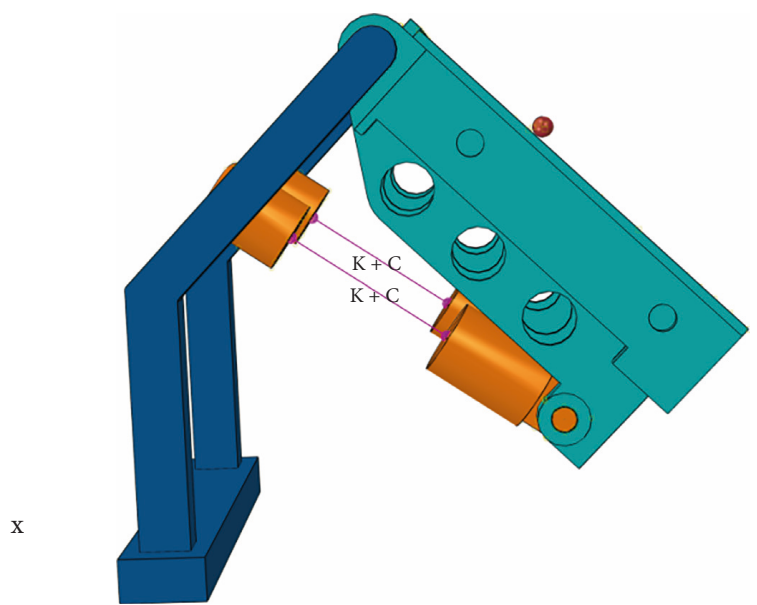

(b)

FIGURE 12: Settings of (a) the boundary conditions and (b) the equivalent spring.

coefficient are set among which the former is calculated to be $2.12253 \times 10^{8} \mathrm{~N} / \mathrm{m}^{3 / 2}$ in accordance with equation (4) and Figure 13 (the structure and size diagram of the jack of the tail beam). The spring damp only changes the response time but has no effect on the response process. Therefore, the damping coefficient of the spring is set as 12,000 in order to accelerate the response rate.

4.3. Simulation Types. Material properties have an effect on the contact stiffness and then on the system response in the process of impact contact. The height of the falling body determines the initial contact velocity, and the impact position of the tail beam affects the stress state of the impact system. Therefore, both the falling height of the coal gangue particles and the impact position of the tail beam have influences on the system response during the impact-contact process. In order to study the influences of material properties, size of the impacted object, height of the falling body, and impact position of the tail beam on the system contact response, four different simulations are carried out in ABAQUS software, respectively: the coal gangue particles impact the tail beam from different heights, the coal gangue particles impact different positions of the tail beam, coal gangue particles with different radii impact the tail beam, and the coal gangue particles with different materials impact the tail beam.
4.3.1. Different Impact Heights. Take falling height of coal particles from the free falling position to the position where particles initially contact with the tail beam as $2 \mathrm{~m}, 2.5 \mathrm{~m}$, $3 \mathrm{~m}, 3.5 \mathrm{~m}$, and $4 \mathrm{~m}$, respectively. The material parameters of particles, the tail beam, and other components (both are Q345) are shown in Table 1.

During the establishment of the 3D model, it has been mentioned that because of the complexity and time-consuming calculation of the model, the free falling increasing process of the particles is replaced by applying a certain initial velocity to the coal particles. The $0.008 \mathrm{~m}$ gap between the particles and the metal plate of the overlaying strata of the tail beam is reserved (which has little effect on the velocity). It is calculated that the initial velocities of the five groups of simulations at different heights are $6.261 \mathrm{~m} / \mathrm{s}, 7 \mathrm{~m} / \mathrm{s}, 7.668 \mathrm{~m} / \mathrm{s}$, $8.368 \mathrm{~m} / \mathrm{s}$, and $8.854 \mathrm{~m} / \mathrm{s}$, respectively. The lateral coordinate of the impact position is $-1 \mathrm{~m}$, as shown in Figure 14. And the rest settings of the simulation are shown in Table 2. The simulation time of each group is $0.05 \mathrm{~s}$.

4.3.2. Different Impact Positions. Take the falling height of the coal particles from the free falling position to the position where particles initially contact with the tail beam as $3.5 \mathrm{~m}$. In other words, the initial velocity applied to the coal particles is $8.368 \mathrm{~m} / \mathrm{s}$. During the modeling process, the 


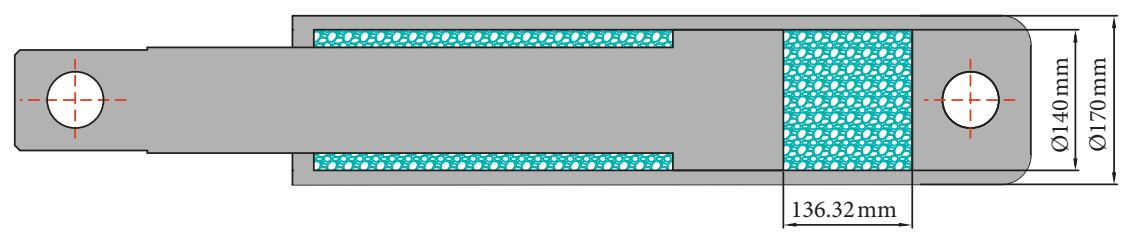

Figure 13: Dimension and structure diagram of the jack of the tail beam.

TABle 1: Parameters of coal particles and Q345.

\begin{tabular}{lccc}
\hline Materials & Density $\left(\mathrm{kg} / \mathrm{m}^{3}\right)$ & Young's modulus $(\mathrm{Pa})$ & Poisson's ratio \\
\hline Coal & 1380 & $2.20 e+9$ & 0.28 \\
Q345 & 7850 & $2.06 e+11$ & 0.3 \\
\hline
\end{tabular}
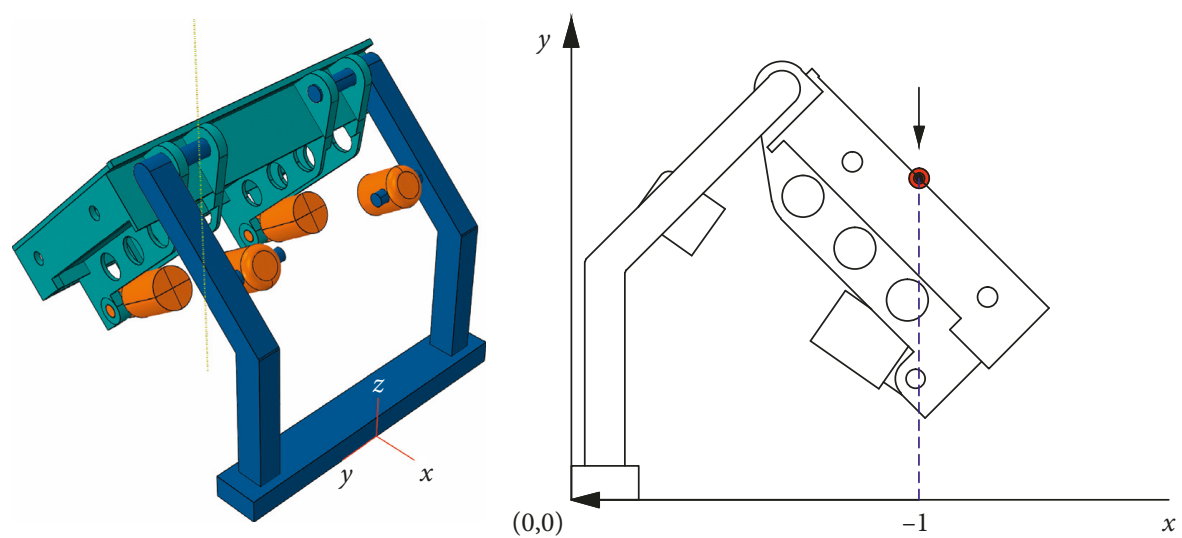

FIGURE 14: Impact position.

TABLE 2: Partial simulation parameters at different impact heights.

\begin{tabular}{lccc}
\hline Simulation group & Particle falling height $($ corresponding initial velocity) & $X$ coordinate $(\mathrm{m})$ & Particle material \\
\hline Job-1 & $2 \mathrm{~m}(6.261 \mathrm{~m} / \mathrm{s})$ & -1 & Coal \\
Job-2 & $2.5 \mathrm{~m}(7 \mathrm{~m} / \mathrm{s})$ & -1 & Coal \\
Job-3 & $3 \mathrm{~m}(7.668 \mathrm{~m} / \mathrm{s})$ & -1 & Coal \\
Job-4 & $3.5 \mathrm{~m}(8.368 \mathrm{~m} / \mathrm{s})$ & -1 & Coal \\
Job-5 & $4 \mathrm{~m}(8.854 \mathrm{~m} / \mathrm{s})$ & -1 & Coal \\
\hline
\end{tabular}

particle center is set to be corresponding to different abscissa $x$ so that the particles can impact different positions of the tail beam. The material parameters of particles, the tail, and other components (both are Q345) are shown in Table 1. The simulation time of each group is $0.05 \mathrm{~s}$, and the rest settings of the simulation are shown in Table 3. Figure 15 shows the different impact positions.

4.3.3. Different Sizes of the Impact Object. Also, take the falling height of the coal particles from the free falling position to the position where particles initial contact with the tail beam as $3.5 \mathrm{~m}$, i.e., the initial velocity applied to the coal particles is $8.368 \mathrm{~m} / \mathrm{s}$. The lateral coordinate of the impact position is $-1 \mathrm{~m}$, as shown in Figure 14. The radii of the coal particles are $0.025 \mathrm{~m}, 0.030 \mathrm{~m}, 0.035 \mathrm{~m}$, and $0.040 \mathrm{~m}$, respectively. The material parameters are shown in Table 1, and the simulation time of each group is $0.05 \mathrm{~s}$.
TABLE 3: Parameters at different positions.

\begin{tabular}{lccc}
\hline Group & Height & $x(\mathrm{~m})$ & Material \\
\hline Job-6 & $3.5 \mathrm{~m}$ & -1.25 & Coal \\
Job-7 & $3.5 \mathrm{~m}$ & -1.20 & Coal \\
Job-8 & $3.5 \mathrm{~m}$ & -1.15 & Coal \\
Job-9 & $3.5 \mathrm{~m}$ & -1.10 & Coal \\
Job-10 & $3.5 \mathrm{~m}$ & -1.05 & Coal \\
Job-4 & $3.5 \mathrm{~m}$ & -1.00 & Coal \\
Job-11 & $3.5 \mathrm{~m}$ & -0.95 & Coal \\
Job-12 & $3.5 \mathrm{~m}$ & -0.90 & Coal \\
Job-13 & $3.5 \mathrm{~m}$ & -0.85 & Coal \\
Job-14 & $3.5 \mathrm{~m}$ & -0.80 & Coal \\
Job-15 & $3.5 \mathrm{~m}$ & -0.75 & Coal \\
\hline
\end{tabular}

4.3.4. Different Impact Materials. Take the falling height of the coal gangue particles from the free falling position to the position where particles initially contact with the tail beam as $3.5 \mathrm{~m}$. The lateral coordinate of the impact position is 


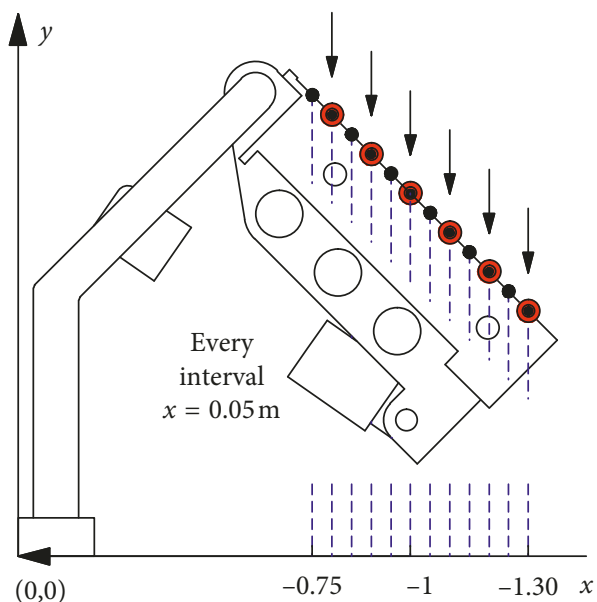

FIgURe 15: Different impact positions.

$X=-1 \mathrm{~m}$, as shown in Figure 14. Coal gangue materials are taken from the coal, the sandstone, and marble, and the material parameters are shown in Table 4 . Table 4 also shows the material parameters of the tail beam and other components (all are Q345). The simulation time of each group is $0.05 \mathrm{~s}$.

\section{Results, Discussion, and Analysis}

5.1. Contact Response of the System with Different Impact Heights. Coal-like rock sphere shows different impact velocities and impact energy when it impacts the tail beam from different heights. Under various impact heights, the curves of the spring stress, the system contact force, the acceleration and velocity of the rigid element close to the hinged hole of the tail beam, and the acceleration and velocity of the coal-like rock sphere are shown in Figures 16-21. In this paper, the acceleration and velocity of the rock sphere extracted from the simulation refer to the corresponding data of the center node of the rock sphere. Due to the violent vibration of the selected rigid node of the tail beam, the acceleration curve of the rigid node close to the hinged hole of the tail beam is processed by FFT for standard analysis.

As shown Figures 16-21, as the simulation time changes and under different impact velocities (i.e., different impact heights), the form of curves of the spring stress, the contact force between the rock sphere and the tail beam, the vibration velocity of the selected rigid node of tail beam, and the vibration velocity and acceleration of the rock sphere are all the same. And they all grow as the impact velocity increases. The reason is that when the rock sphere impacts the tail beam from different heights, the higher the height is, the stronger the impact velocity is. Furthermore, the initial impact energy in the impact-contact system composed of the rock sphere and the tail beam is larger, which leads to increases in above contact responses. The contact force only occurs in the very short time when the rock sphere impacts the tail beam. After the impact, it disappears and the reciprocating vibration of the spring occurs, which causes the tail beam to reciprocate and vibrate. Under the action of the
TABLE 4: Material parameters of coal gangue and Q345.

\begin{tabular}{lccc}
\hline Material & Density $\left(\mathrm{kg} / \mathrm{m}^{3}\right)$ & Young's modulus (Pa) & $\begin{array}{c}\text { Poisson's } \\
\text { ratio }\end{array}$ \\
\hline Coal & 1380 & $2.20 e+9$ & 0.28 \\
Sandstone & 2487 & $1.35 e+10$ & 0.123 \\
Marble & 2800 & $3.40 e+10$ & 0.3 \\
Q345 & 7850 & $2.06 e+11$ & 0.3 \\
\hline
\end{tabular}

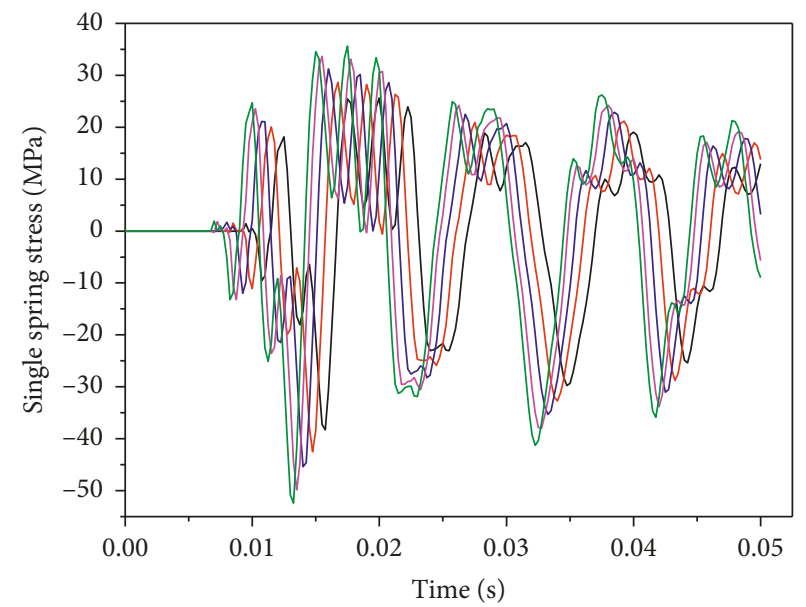

$$
\begin{aligned}
& -v=6.261 \quad-v=8.854 \\
& -v=8.368 \quad-v=7.668 \\
& -v=7
\end{aligned}
$$

FIGURE 16: Spring stress.

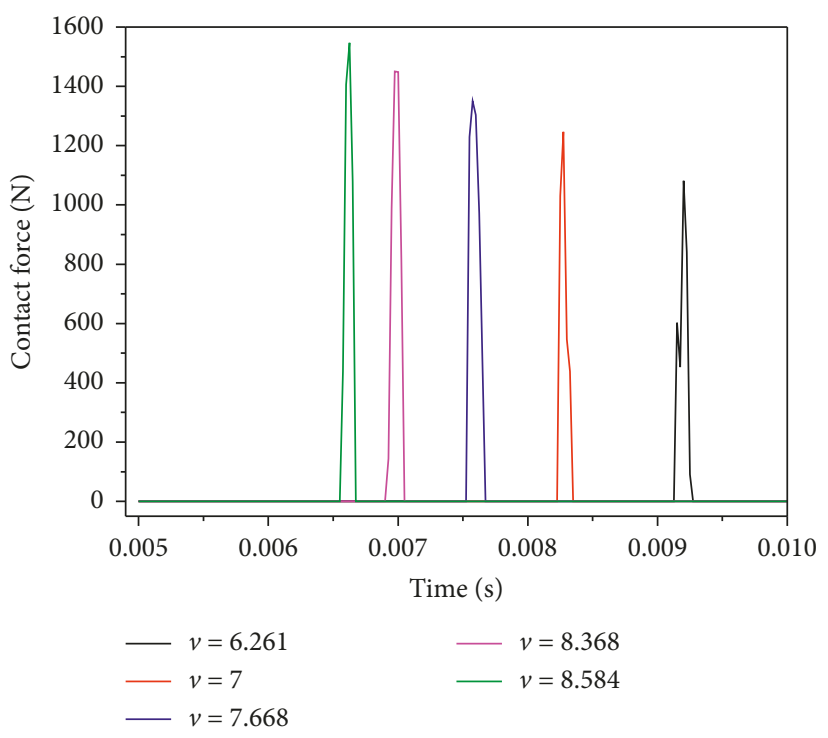

FIgURe 17: Contact force.

spring, the vibration velocity of the selected rigid node presents an approximately periodic reciprocating fluctuation that increases firstly and decreases secondly. In addition, the vibration amplitude of the tail beam gradually declines. After the impact, the velocity and acceleration curves of the rock sphere quickly remain steady. 


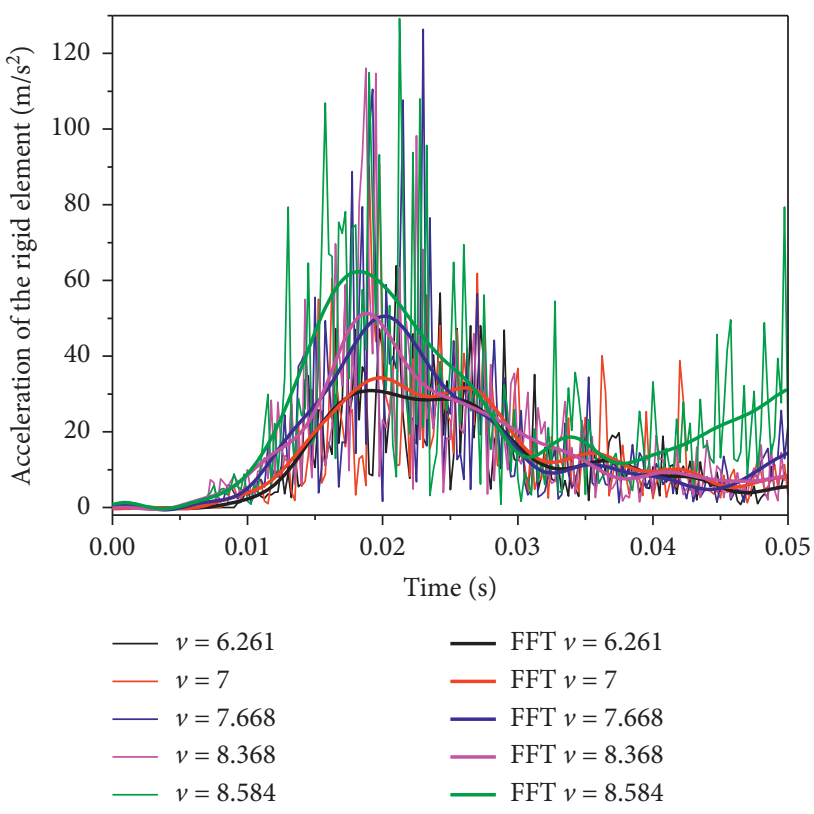

Figure 18: Acceleration of the tail beam.

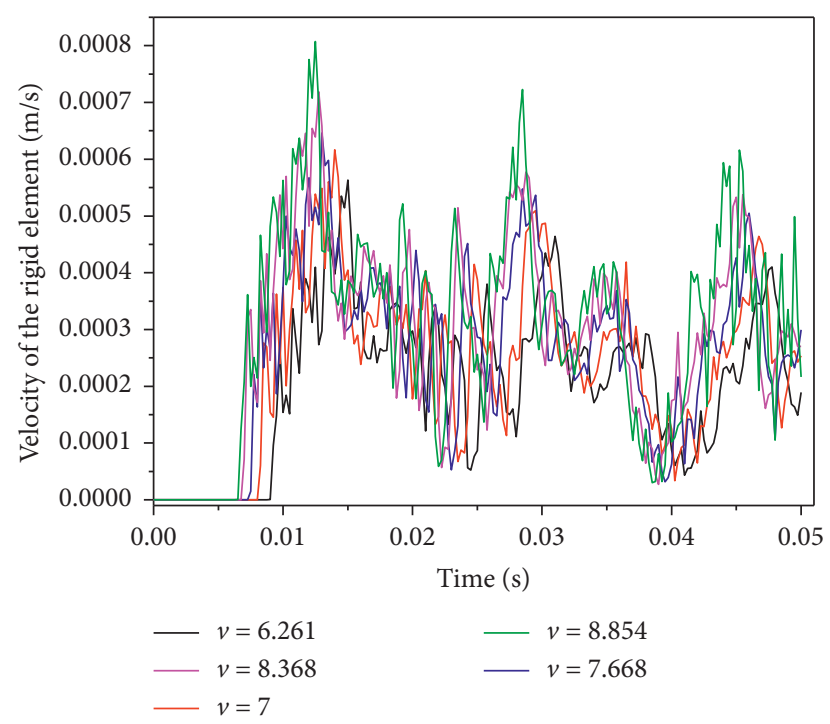

Figure 19: Velocity of the tail beam.

The maximum spring stress (which is defined as the absolute value of the minimum negative value of the spring stress curve) at different impact heights, the maximum system contact force, the maximum acceleration (after FFT treatment) and velocity of the selected rigid node of the tail beam, and the maximum acceleration and velocity of the coal-like rock sphere are extracted. As a result, the maximum contact response of the system at different impact height is obtained, as shown in Figure 22. As the impact height rises, the maximum spring stress, the maximum system contact force, and the maximum acceleration and velocity of the coal-like rock sphere gradually increase while their growth rates decrease. The acceleration of the rigid node close to the hinged hole of the tail beam increases in linear approximation, and its velocity as well as the growth rate increases

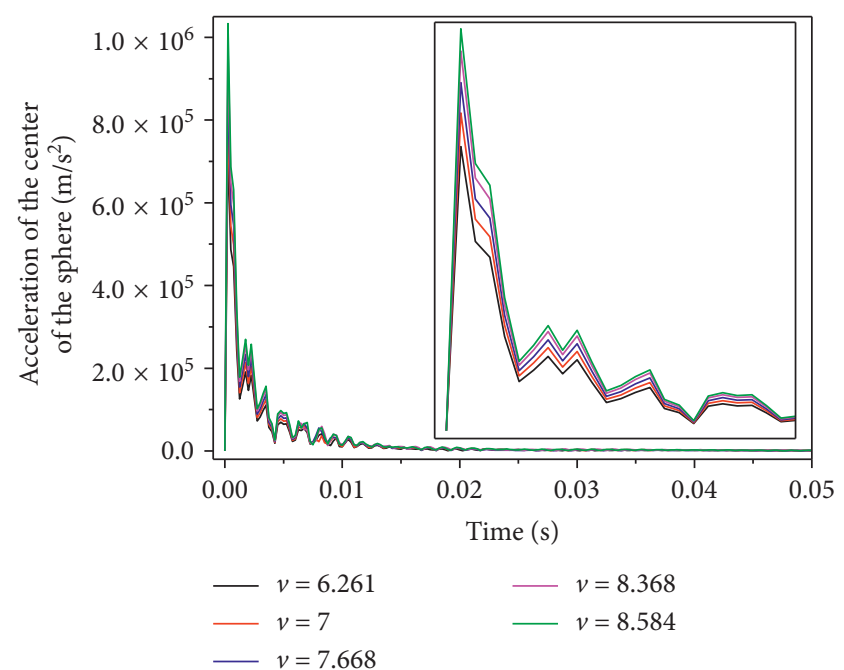

Figure 20: Acceleration of the sphere.

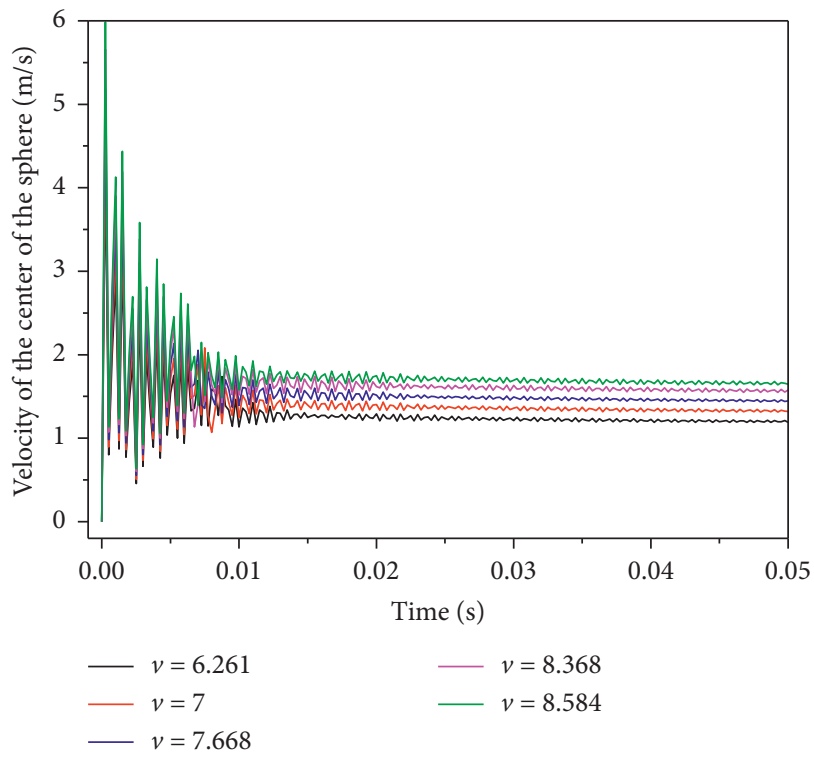

FIGURE 21: Velocity of the sphere.

gradually. It can be seen that the greater the impact height is, the more obvious the vibration amplitude of the tail beam is. The vibration amplitude of the tail beam varies sharply with the increase of impact height. The maximum rebound velocities of five rock spheres is $4.23424 \mathrm{~m} / \mathrm{s}, 4.73325 \mathrm{~m} / \mathrm{s}$, $5.18517 \mathrm{~m} / \mathrm{s}, 5.65751 \mathrm{~m} / \mathrm{s}$, and $5.98562 \mathrm{~m} / \mathrm{s}$, respectively. And their corresponding impact velocities are $6.261 \mathrm{~m} / \mathrm{s}, 7 \mathrm{~m} / \mathrm{s}$, $7.668 \mathrm{~m} / \mathrm{s}, 8.368 \mathrm{~m} / \mathrm{s}$, and $8.584 \mathrm{~m} / \mathrm{s}$. The comprehensive recovery coefficients (defined as the ratio of the total rebound velocity to the initial contact velocity) of the five groups of rock spheres with different impact heights are 0.676288132 , $0.6761781,0.67620892,0.676088671$, and 0.697299627 , respectively. The variation of the comprehensive recovery coefficient at different impact heights is very small.

5.2. Contact Response of the System with Different Impact Positions. The tail beam is sustained by the supporting 

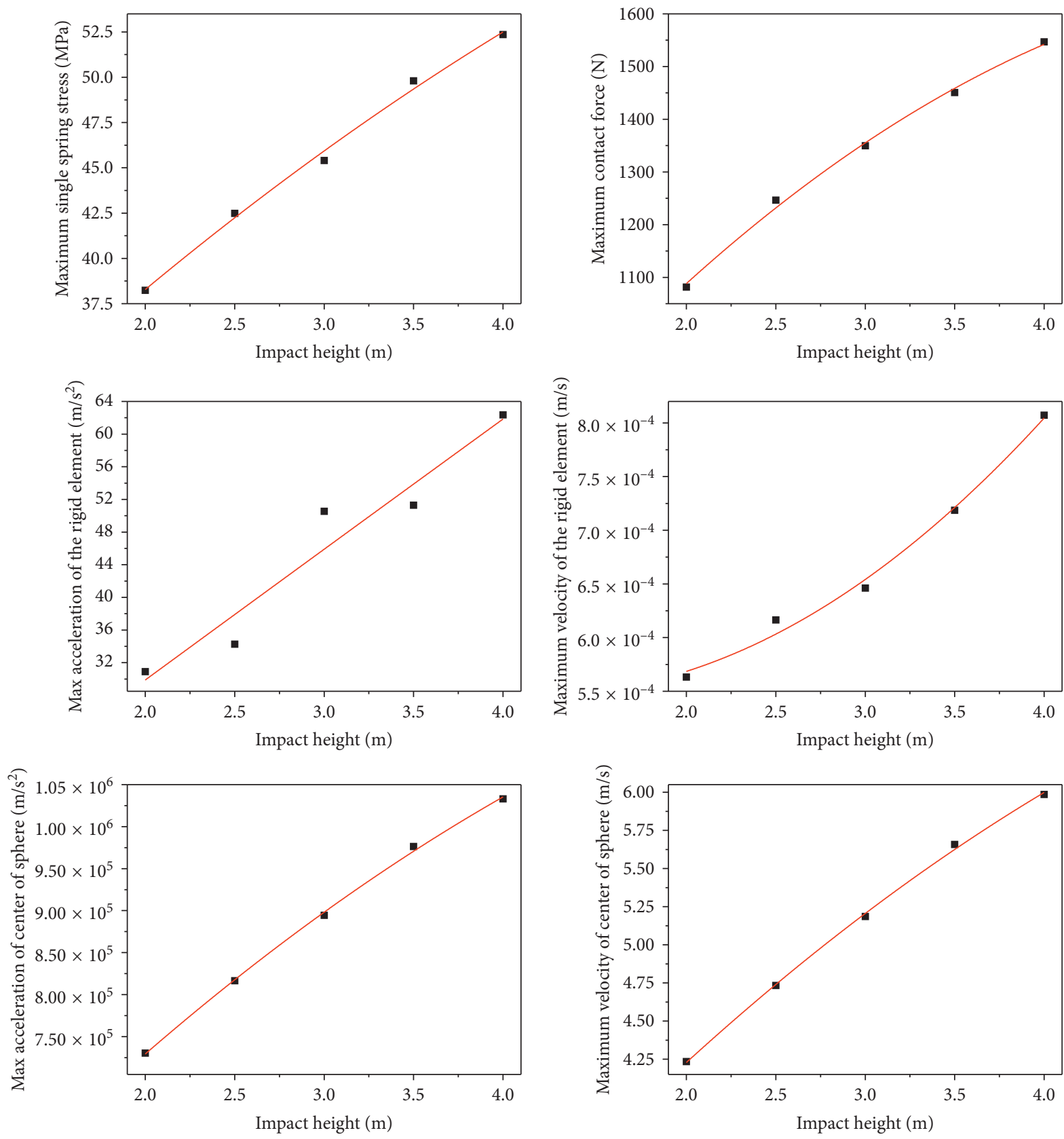

Figure 22: Maximum contact response.

frame and the jack of the tail beam. Under the impactcontact force of the coal-like rock sphere, a four-in-one impact response system composed by the rock sphere, the tail beam, the jack of the tail beam, and the supporting frame is formed. If the rock sphere impacts the different positions of the tail beam, the distance between the contact position of the tail beam and the rigid support terminus of the tail beam (the support terminus by the supporting frame) is different, as well as between the contact position and the elastic support terminus (the support terminus by the jack). As a result, structural stress of the impact system changes and then affects the system impact-contact response. When the rock sphere impacts different positions of the axis of the tail beam at the same velocity, the curves of the spring stress, the system contact force, the acceleration and velocity of the selected rigid node of the tail beam, and the acceleration and velocity of the coal-like rock are shown in Figures 23-28. In addition, the acceleration curve of the rigid element close to the hinged hole of tail beam is also treated by FFT.

It can be seen from the Figures 23-28 that the curves of the system contact response are different when the coal-like rock spheres with the same radius impact different positions of the tail beams at the same velocity, and they does not change monotonically with the change of the impact position. The velocity and acceleration of the rock sphere are approximately the same during the impact process, which indicates that the residual energy of the rock sphere is almost constant when the rock sphere impacts the different 


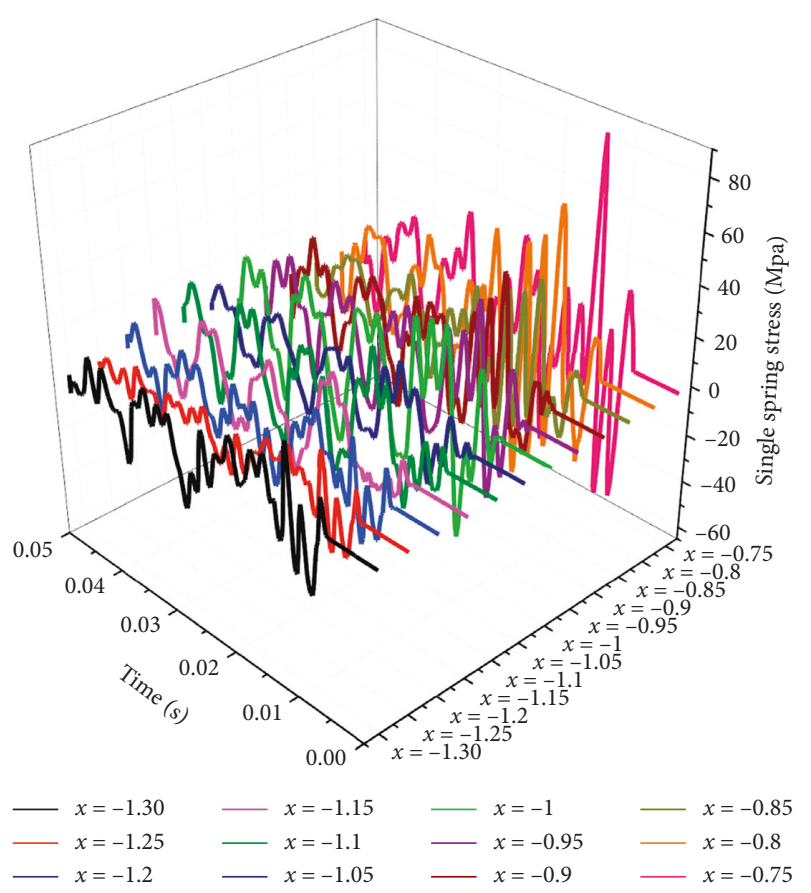

Figure 23: Spring stress.
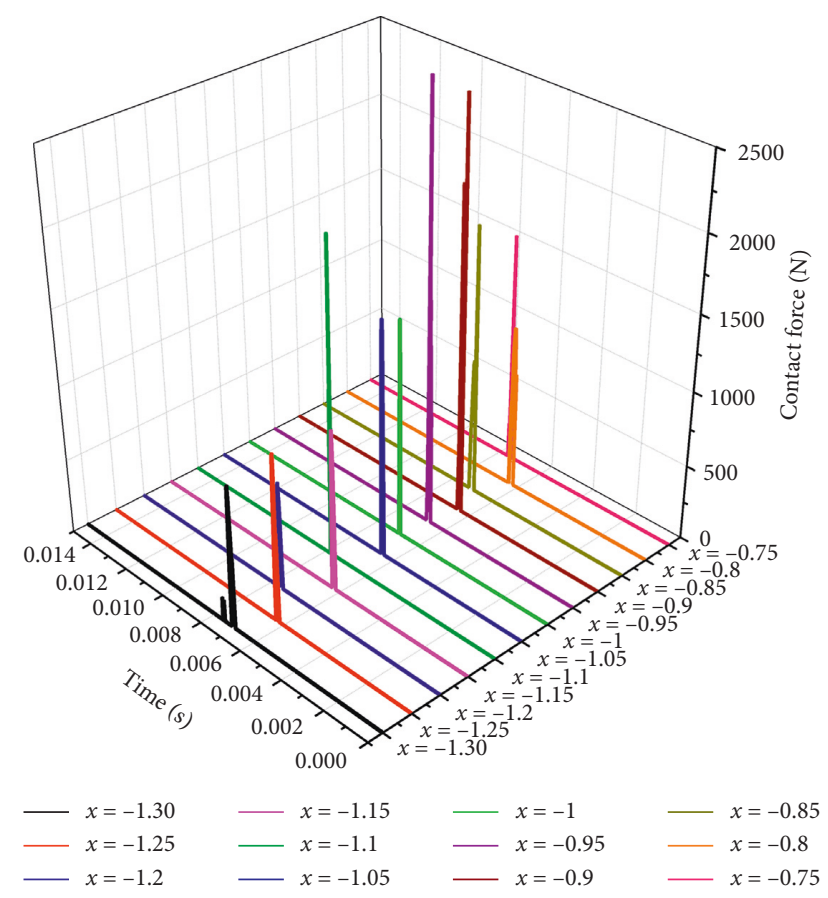

Figure 24: Contact force.

positions of the tail beam, and the total amount of the energy transferred to the tail beam and the spring from the rock sphere is approximately the same. In order to analyze the law of system response further, the maximum spring stress (which is defined as the absolute value of the minimum negative value of the spring stress curve) at different impact heights, the maximum system contact force, the maximum acceleration (after FFT treatment) and velocity of the

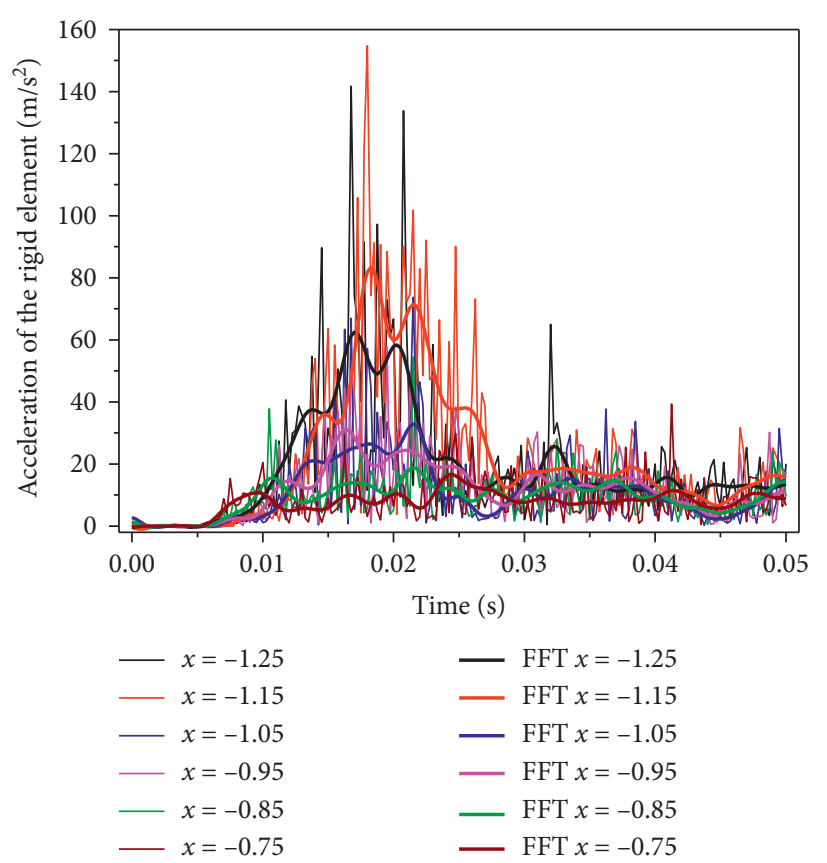

Figure 25: Acceleration of the tail beam.

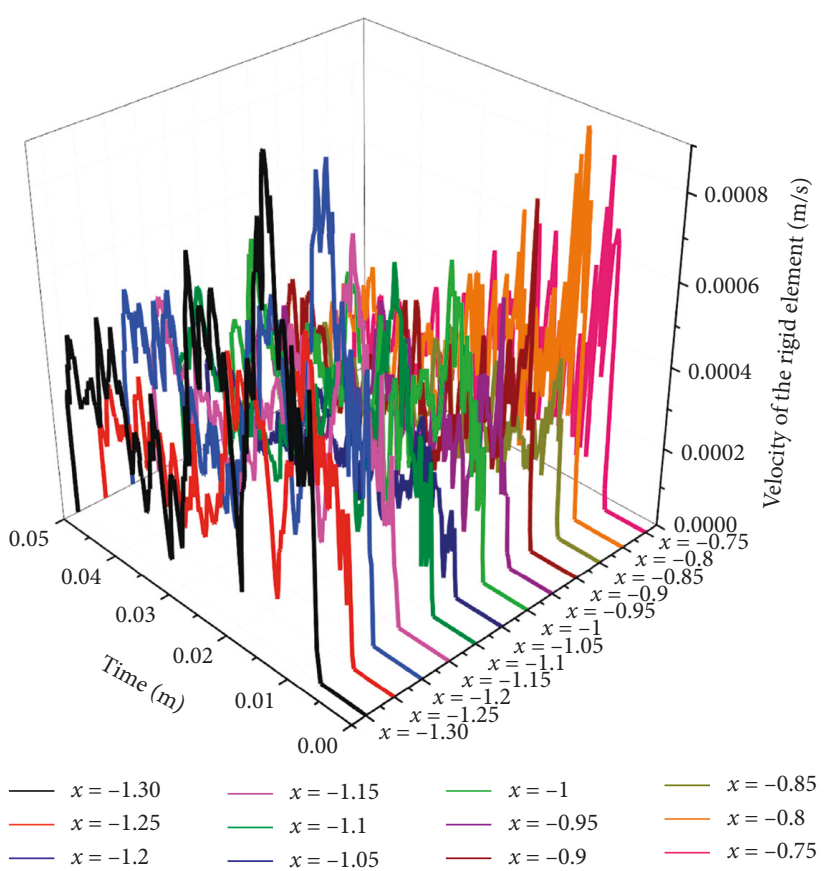

FIgURe 26: Velocity of the tail beam.

selected rigid node of the tail beam, and the maximum acceleration and velocity of the coal-like rock sphere are extracted. Figure 29 shows the maximum system contact response.

Figure 29 shows that as the impact position changes, the maximum value of the maximum spring stress appears when the rock sphere impacts the tail beam near the support terminus of the spring. Maximum spring stress decreases first and then increases when the impact 


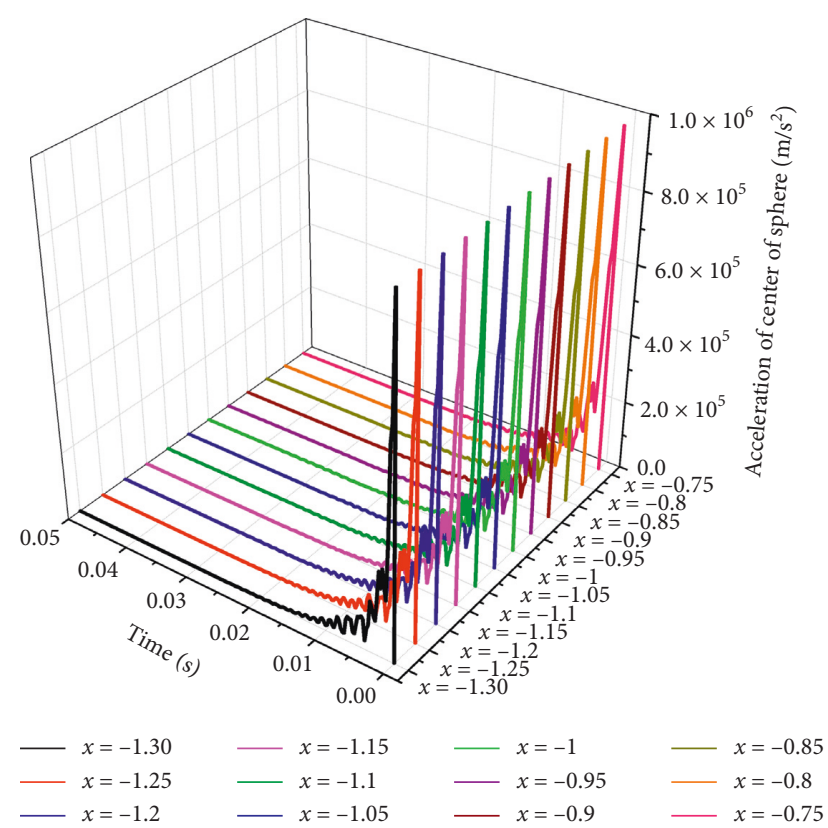

FIgURE 27: Acceleration of the sphere.

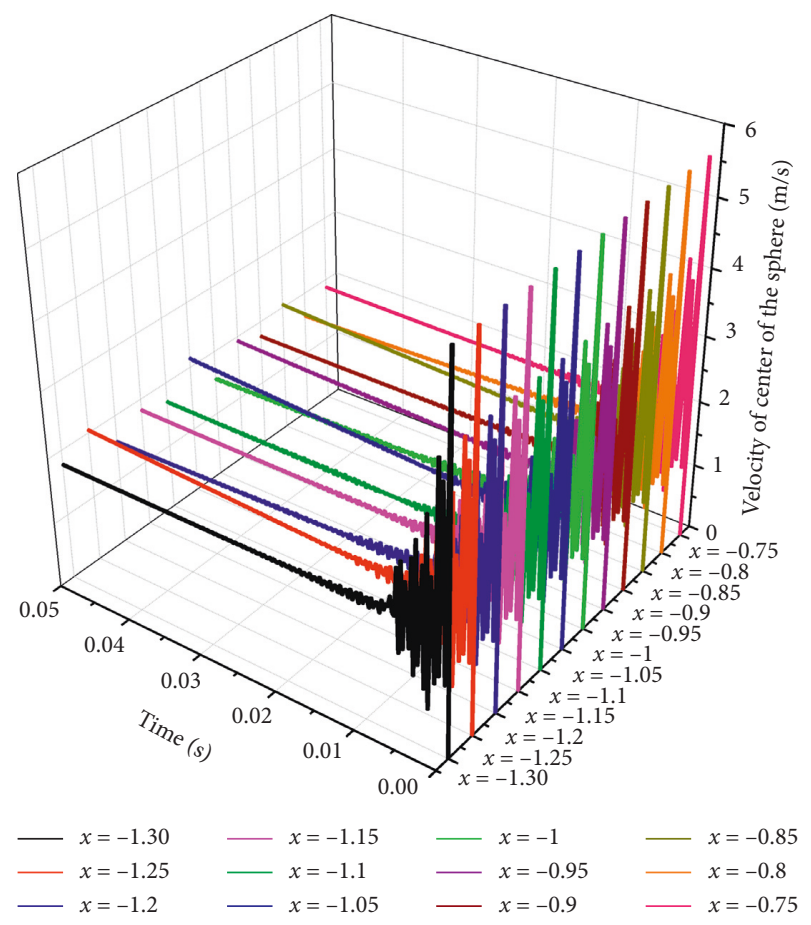

FIGURE 28: Velocity of the sphere.

position moves away from the support terminus of the spring. And when it comes near to $x=-1 \mathrm{~m}$, the maximum value of the maximum spring stress appears again. When the impacted position continues to approach the rigid support terminus, the maximum spring stress decreases again and it increases slightly near the terminus. The trend of the maximum spring stress of the system, as a whole, appears decrease $\longrightarrow$ increase $\longrightarrow$ decrease $\longrightarrow$ increase $\longrightarrow$ decrease $\longrightarrow$ increase (the direction is from the support terminus of the spring to the rigid support terminus, i.e., $x=-1.3 \mathrm{~m} \longrightarrow x=-0.75 \mathrm{~m})$. And the minimum value of the maximum spring stress of the system appears around $x=-1.25 \mathrm{~m}$. The maximum contact force of the system, as a whole, shows an increase $\longrightarrow$ decrease $\longrightarrow$ increase $\longrightarrow$ decrease $\longrightarrow$ increase trend. The maximum contact force reaches its maximum value around $x=-0.95 \mathrm{~m}$ while its minimum value appears near $x=-1.2 \mathrm{~m}$. That is, the minimum value of the maximum contact force occurs at a short distance from the support terminus of the spring, and the minimum value of the maximum contact force appears close to the center of the tail beam but slightly biased toward the fixed support terminus. The maximum acceleration belonging to the selected rigid node of the tail beam shows a decrease $\longrightarrow$ increase $\longrightarrow$ decrease $\longrightarrow$ increase trend (the oscillation changes after $x>-1.2 \mathrm{~m}$ is considered to be decreasing all the time). The maximum value of the maximum acceleration of the selected rigid node occurs at $x=-1.3 \mathrm{~m}$ that is closest to the support terminus of the spring. And the minimum value of the maximum acceleration occurs at $x=-0.75 \mathrm{~m}$ which is closest to the rigid support terminus. The maximum velocity of the selected rigid node shows the trend of decreasing $\longrightarrow$ increasing $\longrightarrow$ decreasing $\longrightarrow$ increasing $\longrightarrow$ decreasing. The maximum value of the maximum velocity of the selected rigid node reaches its maximum value at $x=-1.3 \mathrm{~m}$ which is closest to the support terminus of the spring while it reaches its minimum value at $x=-1.15 \mathrm{~m}$ which is close to the center of the tail beam but slightly biased toward the elastic support terminus (spring). Therefore, the most obvious vibration signal of the tail beam occurs when the support terminus of the spring is impacted. The minimum and maximum values of the maximum acceleration of the rock sphere are $976307 \mathrm{~m} / \mathrm{s}^{2}$ and $976474 \mathrm{~m} / \mathrm{s}^{2}$, respectively. And the minimum and maximum values of the maximum velocity are $5.6572 \mathrm{~m} / \mathrm{s}$ and $5.65799 \mathrm{~m} / \mathrm{s}$, respectively. In addition, the maximum changing rates of the maximum acceleration and velocity are $0.017105 \%$ and $0.013965 \%$, respectively, which can be ignored. So, when the same rock sphere impacts the different positions of the tail beam along the central axis, its comprehensive recovery coefficient hardly changes.

\subsection{Contact Response of the System with Different Impact Sizes.} For impacted objects with the same properties, its different sizes will result in different influences to the contact stiffness, the impact energy, the equivalent contact radius, and the contact area of the system. Moreover, the compression depth of the rock sphere, the contact force, and the structural force of the system are also affected. Therefore, the contact response of the system will be different when the radius of the impacted object is various. As the varisized coal-like rock spheres impact the same position $(x=-1 \mathrm{~m})$ of the tail beam at the same velocity of $8.368 \mathrm{~m} / \mathrm{s}$ (the same impact height), the curves of the spring stress, the system contact force, the acceleration and velocity of the rigid node of the tail beam, 

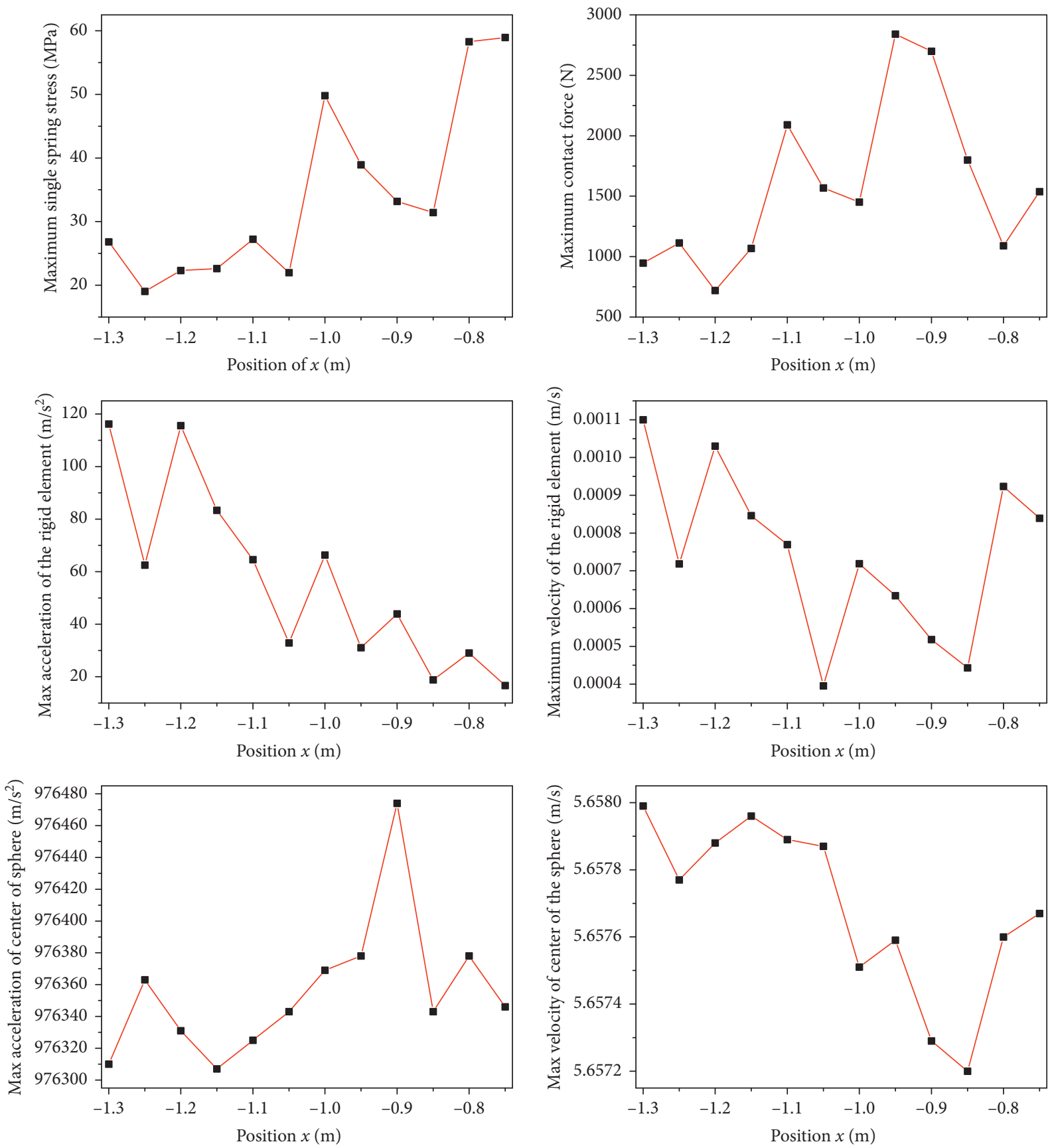

FIgURE 29: Maximum contact response.

and the acceleration and velocity of the coal-like rock sphere are shown in Figures 30-35. And the acceleration curve of the rigid node close to the hinged holes of the tail beam (Figure 32) is processed by FFT.

As shown in Figures 30-35, when the coal-like rock spheres with the different radius impact the same position of the tail beam at the same velocity, the curve form of the spring stress, the vibration velocity of the selected rigid node of the tail beam and the velocity and acceleration of the rock sphere is the same as the simulation time varies. As the radius of the coal-like rock sphere increases, the spring stress, the contact force between the rock sphere, and the tail beam as well as the vibration velocity and acceleration of the selected rigid node of the tail beam increase, while the velocity and acceleration of the rock sphere decrease. The reason is that the material properties remain constant, the larger the radius of the rock sphere is, the greater the Hertz contact stiffness of the system is. Furthermore, the mass and the initial impact energy of the coal-like rock sphere also increase. As a result, the contact force between the rock sphere and the tail beam increases and more energy is transferred to the tail beam when it is impacted. Therefore, the vibration velocity and acceleration of the rigid node of the tail beam increase. The 


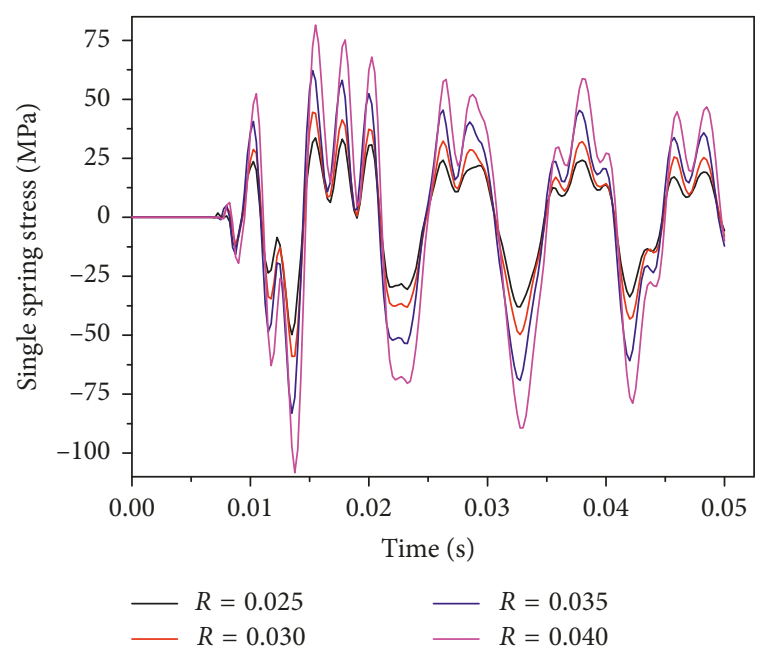

FIgURE 30: Spring stress.

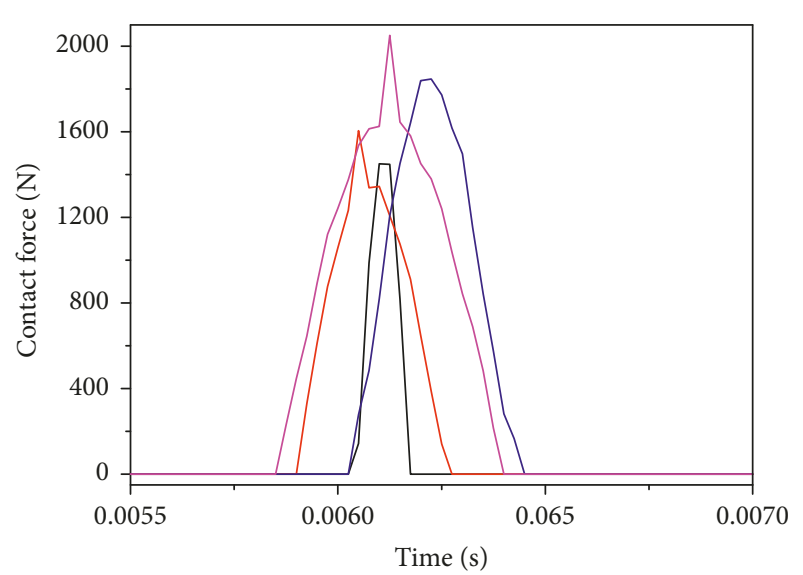

$$
\begin{array}{rlrl}
R & =0.025 \\
R & =0.030 & -R & =0.035 \\
-R & =0.040
\end{array}
$$

Figure 31: Contact force.

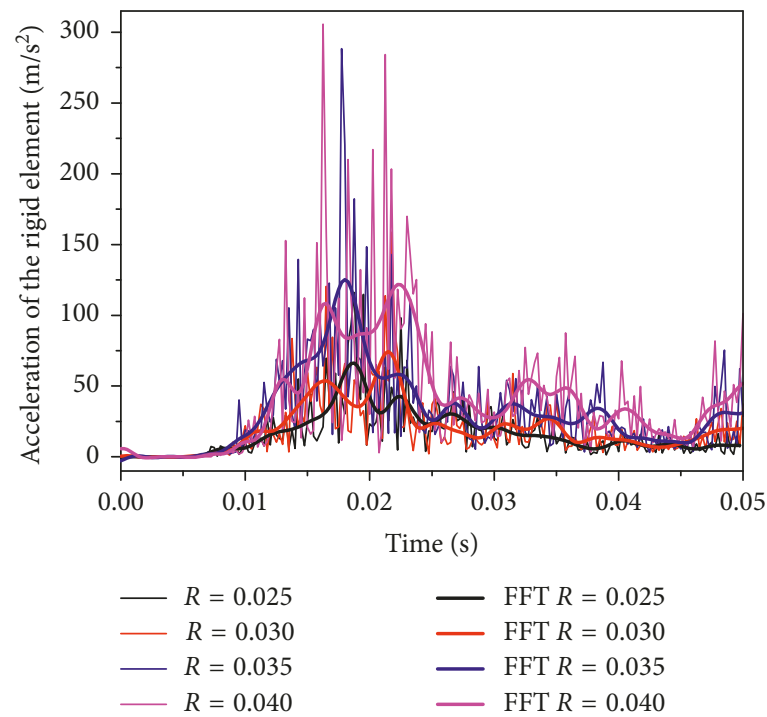

Figure 32: Acceleration of the tail beam.

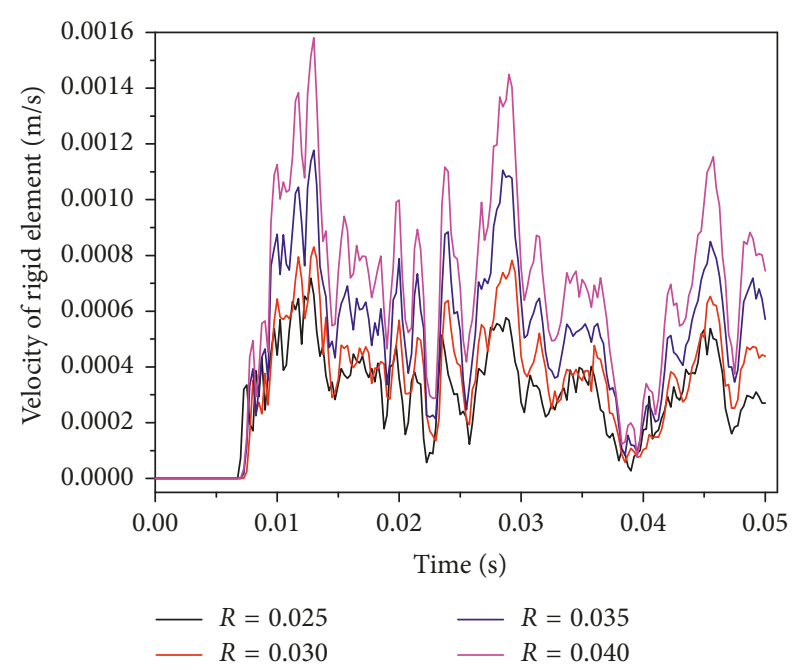

Figure 33: Velocity of the tail beam.

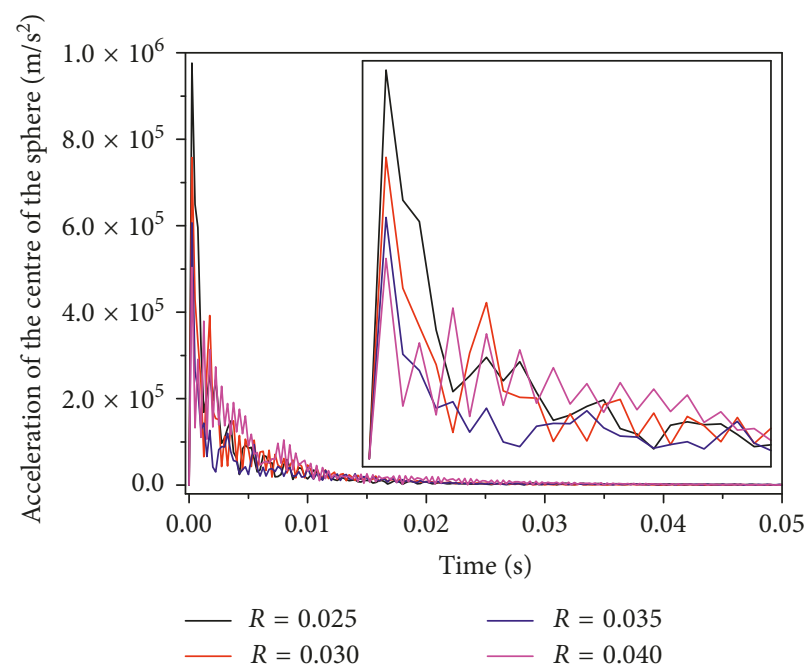

FIgURE 34: Acceleration of the sphere.

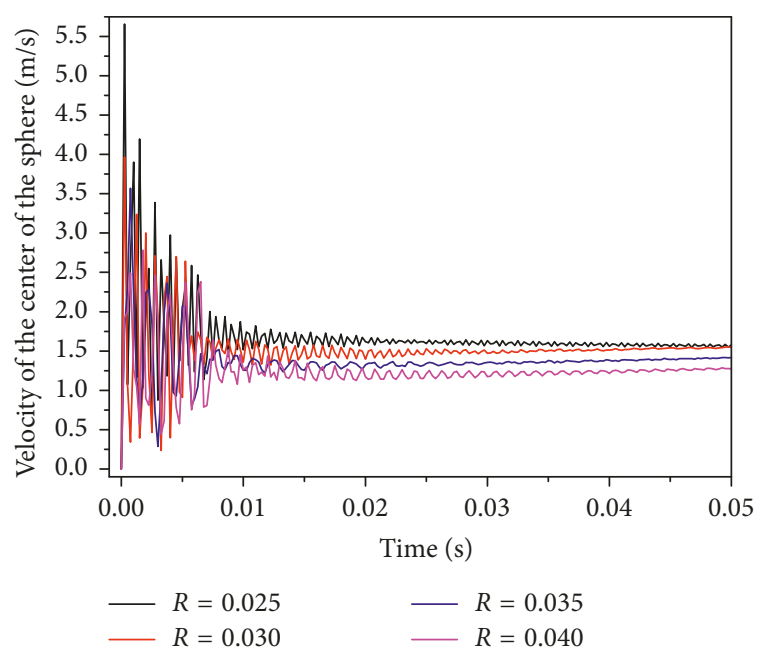

FIGURE 35: Velocity of the sphere. 
energy transferred to the tail beam increases, resulting in that the ratio of the energy of the coal-like rock sphere to its initial impact energy decreases after impact contact. Furthermore, after the impact-contact process, the larger the radius of the rock sphere is, the smaller the velocity and acceleration of the rock sphere are. Similarly, the velocity and acceleration curves of the rock sphere quickly remain steady.

The same treatment is also utilized to, respectively, extract the maximum values of the contact responses in Figures 30-35 when the rock spheres with different radii impact the tail beams (where the maximum acceleration of the selected rigid node is equal to the maximum value of the acceleration curve after FFT treatment, and the maximum spring stress is defined as the absolute value of the minimum negative value of the spring stress curve). Then, the maximum contact response of the system at different impact heights is obtained, as shown in Figure 36. According to Figure 36, it can be seen that as the radius of the rock sphere increases, the maximum spring stress, the maximum system contact force, and the velocity of the rigid element close to the hinged hole of the tail beam increase gradually, and their growth rates increase. This shows that the larger the radius of the rock sphere is, the more obvious the vibration amplitude of the tail beam is. And the acceleration of the rigid node close to the hinged hole of the tail beam increases gradually while its growth rate decreases slightly. As the radius of the rock sphere increase, its maximum velocity and acceleration decrease and the decreasing rate gradually slows down. The impact velocities of rock spheres are $8.368 \mathrm{~m} / \mathrm{s}$, and the maximum rebound velocities of four groups of rock spheres with different radii are $5.65751 \mathrm{~m} / \mathrm{s}, 3.96624 \mathrm{~m} / \mathrm{s}, 3.57084 \mathrm{~m} /$ $\mathrm{s}$, and $2.78333 \mathrm{~m} / \mathrm{s}$, respectively. And their comprehensive recovery coefficients are $0.676088671,0.473977055$, 0.426725621 , and 0.332615917 , respectively. When the rock sphere impacts the tail beam, the comprehensive recovery coefficient of the rock sphere decreases as its radius increases.

5.4. Contact Response of the System with Different Impact Materials. Two kinds of particles coal and gangue can be seen in the process of coal mining. And the properties of coal and gangue under different working faces are also different. The contact stiffness and the damping of the system vary with the material of the contacted object, which leads to the change of the system impact-contact response when the particles impact the tail beam. In this paper, one kind of coal and two different kinds of gangue (sandstone and marble) are considered as the research object, as shown in Table 4. When the different elastic spheres (which are defined as coal elastic sphere, sandstone elastic sphere, and marble elastic sphere) with the same radius, respectively, impact the same position $(x=-1 \mathrm{~m})$ of the tail beam at the same velocity (the same impact height) of $8.368 \mathrm{~m} / \mathrm{s}$, the curves of the spring stress, the system contact force, the acceleration and velocity of the selected rigid node of the tail beam, and the acceleration and velocity of the coal-rock sphere are shown in Figures 37-42.
Figures 37-42 show that when the coal elastic sphere, sandstone elastic sphere, and marble elastic sphere with the same radius impact the tail beam at the same velocity, the curve forms of the spring stress, the vibration acceleration and velocity of the selected rigid node of the tail beam and the vibration acceleration and velocity of the rock sphere are the same as the simulation time changes. When the same position of the tail beam is impacted at the same velocity, the spring stresses, and the vibration velocity of the rigid node of the tail beam produced by the impacts of sandstone and marble elastic spheres with the same radius are almost the same, the impacts of the sandstone elastic sphere are slightly smaller than those of the marble elastic sphere. When the coal-like rock sphere impacts the tail beam, the spring stress, the vibration acceleration and velocity of the selected rigid node of the tail beam, and the acceleration of the rock sphere are far less than those of the sandstone elastic sphere and the marble elastic sphere. However, the velocity law of the rock sphere is contrary (it means that when the rock sphere with the same radius impacts the same position of tail beam at the same velocity, the velocity of the coal elastic sphere is much faster than that of the sandstone elastic sphere and marble elastic sphere).

Figures 37-42 also show that when the coal elastic sphere impacts the tail beam, the maximum single spring stress is $33.685 \mathrm{MPa}$ and the minimum single spring stress is $-49.8086 \mathrm{MPa}$. And the maximum changing value of the single spring stress is $83.4936 \mathrm{MPa}$. Another, when the sandstone elastic sphere impacts the tail beam, the maximum single spring stress is $55.4426 \mathrm{MPa}$ and the minimum single spring stress is $-82.6176 \mathrm{MPa}$, and the maximum changing value of single spring stress is $138.0602 \mathrm{MPa}$. And when the marble elastic sphere impacts the tail beam, the maximum single spring stress is $56.7875 \mathrm{MPa}$ and the minimum single spring stress is $-86.0464 \mathrm{MPa}$. Its maximum changing value of the single spring stress is 142.8339 $\mathrm{MPa}$. According to the data, the maximum spring stresses (which is defined as the absolute value of the minimum negative value of the spring stress curve) of the spring caused by the impacts of the sandstone and marble elastic spheres on the tail beam are 1.6587 times and 1.72754 times of the maximum spring stress caused by the impact of coal elastic sphere. And when the sandstone and marble elastic spheres impact the tail beam, their maximum changes of single spring stresses are 1.65354 times and 1.71072 times of the maximum spring stress caused by the impact of coal elastic sphere. When the gangue-like elastic sphere impacts the tail beam, the spring stress and the maximum changing value of the single spring stress are much greater than those of the impact caused by coal-like elastic sphere. At the same time, it can be known that when the coal, sandstone, and marble elastic spheres impact the tail beam, the maximum contact forces of the system are $1450.72 \mathrm{~N}, 4249.05 \mathrm{~N}$, and 6341.25 , respectively. And the contact forces produced by the impacts of sandstone and marble elastic spheres are 2.92892 times and 4.3711 times that of the coal elastic sphere. The maximum acceleration of the selected rigid node of the tail beams is $116.073 \mathrm{~m} / \mathrm{s}^{2}, 199.969 \mathrm{~m} / \mathrm{s}^{2}$, and $264.017 \mathrm{~m} / \mathrm{s}^{2}$, respectively. When the sandstone and marble elastic spheres 

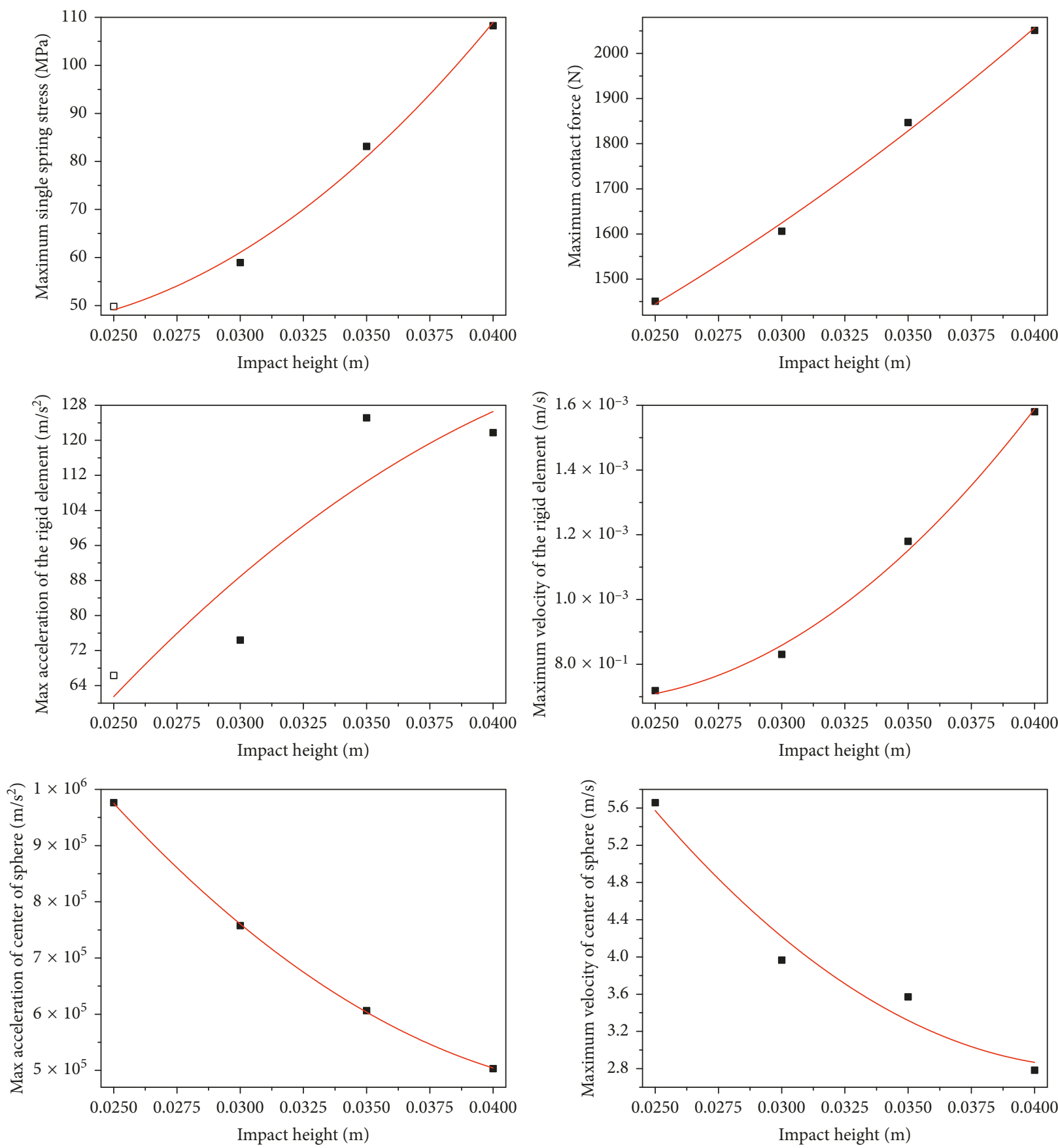

FIGURE 36: Maximum contact response.

impact the tail beam, their maximum acceleration of the selected rigid node is 1.72279 times and 2.27458 times those of the coal elastic sphere. Velocities of the selected rigid node are $0.000718687 \mathrm{~m} / \mathrm{s}, 0.00122 \mathrm{~m} / \mathrm{s}$, and $0.00137 \mathrm{~m} / \mathrm{s}$, respectively. And the maximum velocities of the selected rigid node when the sandstone and marble elastic spheres impact are 1.69754 times and 1.90625 times that of the coal elastic sphere. The maximum acceleration of the rock spheres is $976369 \mathrm{~m} / \mathrm{s}^{2}, 1986110 \mathrm{~m} / \mathrm{s}^{2}$, and $1140600 \mathrm{~m} / \mathrm{s}^{2}$. In addition, the maximum rebound accelerations of the sandstone and marble elastic spheres after their impacts are 2.03418 times and 1.16821 times that of coal elastic sphere. The maximum velocities of the three rock spheres are $5.65751 \mathrm{~m} / \mathrm{s}$, $2.72292 \mathrm{~m} / \mathrm{s}$, and $3.04507 \mathrm{~m} / \mathrm{s}$, respectively. And rebound velocities of sandstone elastic sphere and marble elastic sphere after their impacts are 0.4812 times and 0.53824 times that of coal elastic sphere.

According to the above data, the contact response of coal elastic sphere impacting the tail beam, such as spring stress, system contact force, the acceleration and velocity of the selected rigid node of the tail beam, and the acceleration and velocity of the rock sphere are different from those of the 


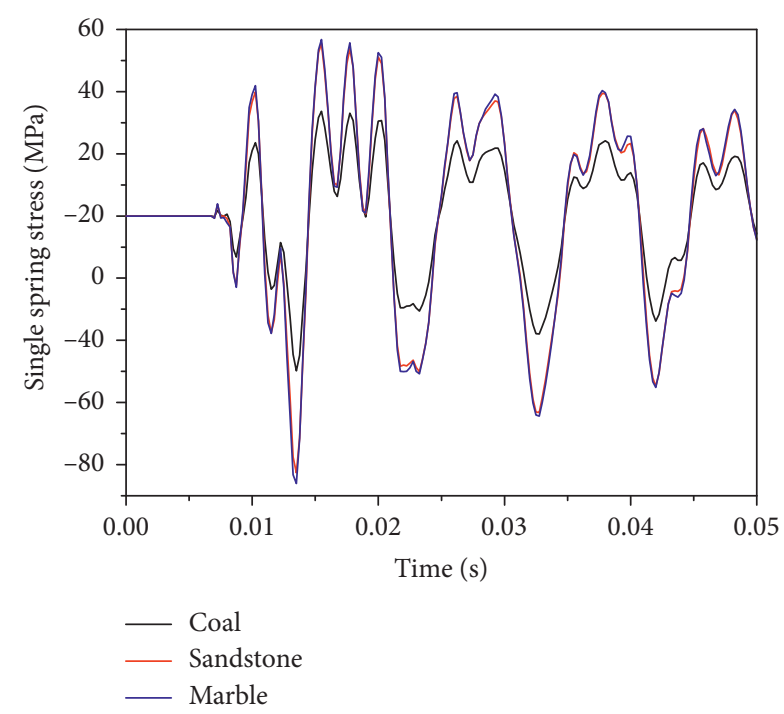

Figure 37: Spring stress.

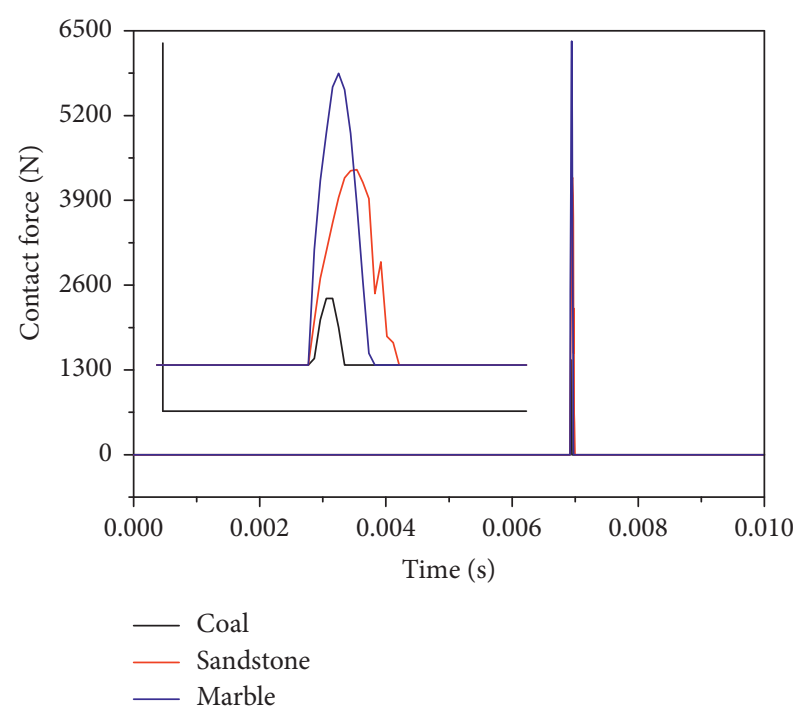

FIGURE 38: Contact force.

impact of gangue elastic sphere. In the simulation model, the spring replaces the jack of the tail beam in the solid model. On the basis of this, when the gangue elastic sphere, respectively, impacts the tail beam, the oil pressure, its variable quantity of the jack, and the vibration velocity of the tail beam after its impact are much larger than the change of the response parameters caused by the impact of coal elastic sphere, while the rebound velocity of the gangue elastic sphere particles is much smaller than that of the coal elastic sphere after the impact. Therefore, in the process of technical researches on the coal gangue identification for longwall top coal caving or on the coal gangue identification of particles impacting the tail beam of the hydraulic support, the oil pressure of the jack of the tail beam after impact can be extracted by the pressure sensor and its

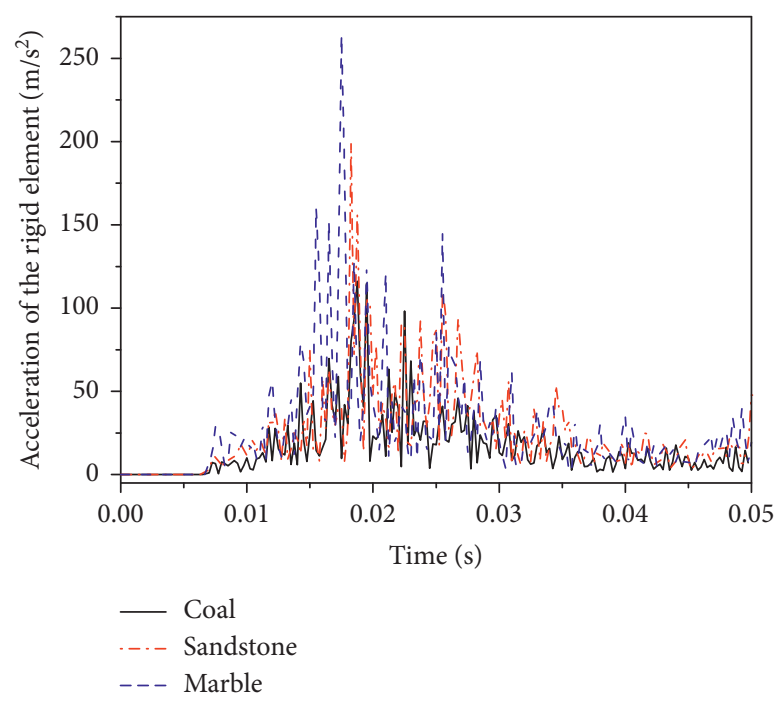

Figure 39: Acceleration of the tail beam.

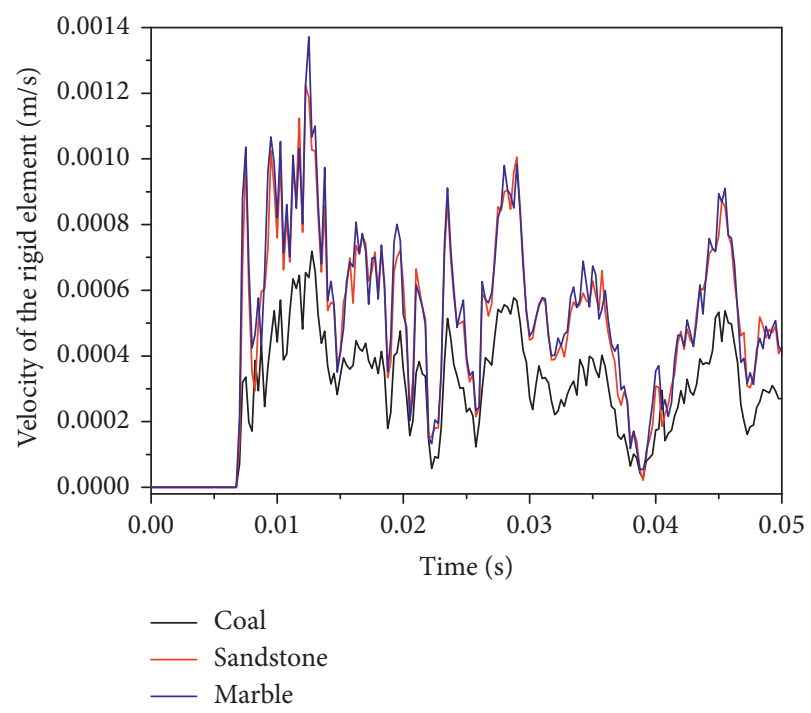

FIgURE 40: Velocity of the tail beam.

changing value can be monitored. The vibration response of the tail beam after impact can be extracted by the velocity or the acceleration sensor, and the rebound velocity of the rock sphere can be pictured by using instruments such as high-speed camera. It is feasible to carry out the gangue identification in accordance with the differences of the measured parameters (note: for a qualitative research, both the coal and gangue particles are equivalent to elastomers in the simulation. Actually, they are brittle objects and coal is easier to break than gangue particles. In actual impact experiment, when the coal and gangue particles impact the tail beam, the differences of the oil pressure and its variable quantity of the jack of tail beam, as well as the vibration velocity of the tail beam after impact will be greater. Based on these parameters, the realizability to perform the coal gangue identification will be higher. However, because of 


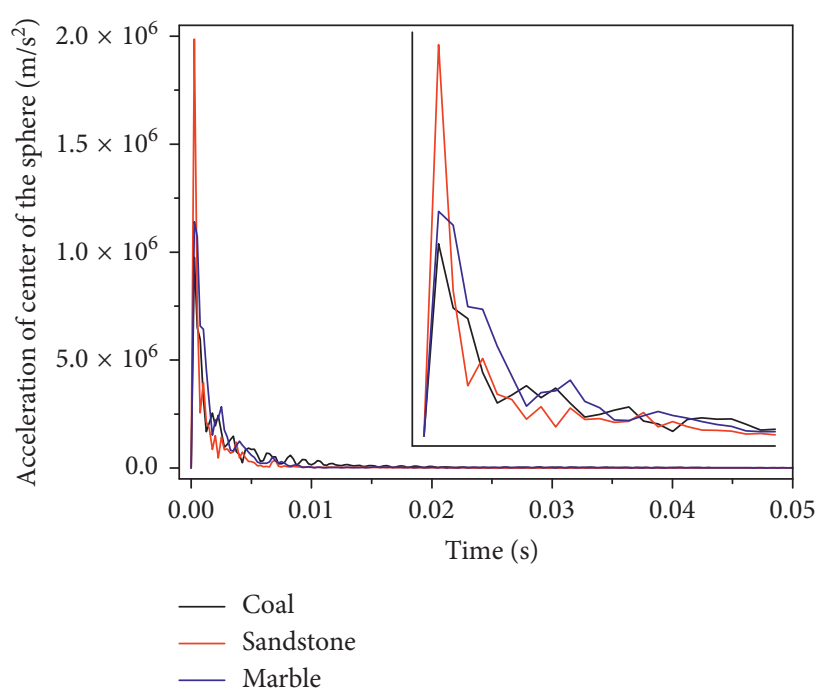

Figure 41: Acceleration of the sphere.

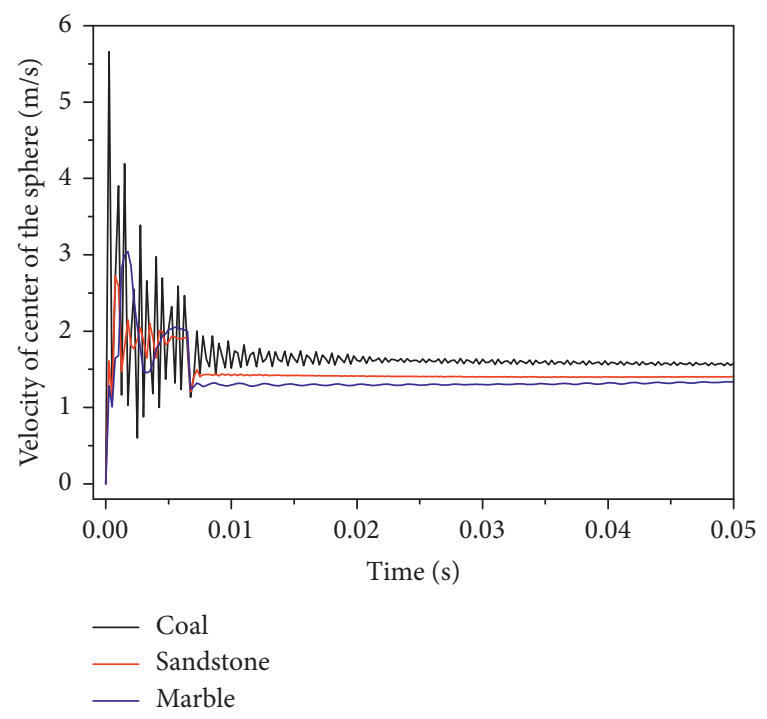

Figure 42: Velocity of the sphere.

the fact that coal is easier to break than gangue particles, the rebound velocity of coal may be smaller than that of gangue in the actual experiment.)

\section{Conclusion}

In the mining of longwall top coal caving, the impactcontact behavior between the coal gangue particles and the tail beam of the hydraulic support often occurs. In order to accurately grasp the dynamic response system of the coal gangue impacting the tail beam, a simplified device model and kinematics model of the tail beam were established in this paper. Furthermore, by combining the equivalent stiffness theory of the jack of the tail beam, the contact model of L-N nonlinear spring damping, and the energy conservation law, the system contact-structure dynamic model of the particles impacting the massless tail beam of hydraulic support was established. On this basis, in order to accurately study the dynamic contact response of the system, the method of finite element simulation was used to carry out the four different types of finite element dynamic simulations: impacts of coal-like elastic particles on the massless tail beam from different heights, coal-like elastic particles on the different positions of central axis of massless tail beam, coal-like elastic particles with different radii on the massless tail beam, and coal gangue-like elastic particles with different materials on the massless tail beam. In a word, the conclusions are as follows:

(1) According to the contact-structure dynamics model of the particles impacting the tail beam of the hydraulic support established in this paper, the system contact response is related to the parameters such as the mass of the impacted object, the properties of the contacted object, the impact height, the impact position, and the initial position of the tail beam when the rock sphere impacts the tail beam.

(2) As the impact height increases, the impact-contact velocity of the same rock sphere (i.e., the initial impact energy) increases. When the same position of the tail beam is impacted, the spring stress of the system, the contact force between the rock sphere and the tail beam, the vibration velocity and acceleration of the selected rigid node of the tail beam, and the velocity and acceleration of the rock sphere increase. And the amplitude of the above contact responses increases accordingly.

(3) The support form of the tail beam consists of the rigid support and the flexible support at the different termini, which can be counted as the composite support. It causes that the structural stress of the system impact response changes when the coal-like rock sphere with the same radius impacts the different positions of the tail beam at the same velocity. And the contact response of the system does not change monotonously when the impact position changes. Maximum rebound velocity and acceleration of the rock sphere are approximately the same after its impact on the different positions of the tail beam, and its residual energy after impact is almost unchanged. When the impact position is located near the rigid support terminus, the maximum value of the maximum spring stress occurs. And when the impact position is close to the middle of the tail beam but slightly biased toward the flexible support terminus, the maximum contact force occurs. Overall observation shows that the vibration amplitude of the tail beam is smaller when the impact position moves to the rigid support terminus. Besides, when the flexible support terminus of the tail beam is impacted, the maximum value of the maximum vibration velocity of the tail beam appears. And when the impact position is close to the middle position of the tail beam $(x=-1.05 \longrightarrow-0.95)$, the curve trends of some system contact responses such as the 
maximum contact force, the maximum spring stress, the vibration velocity, and the acceleration of the tail beam change.

(4) For the elastic sphere with the same material, as the radius of the sphere increases but the material properties remain constant, the Hertz contact stiffness of the system as well as the mass of the sphere increases. In addition, the increase also goes to the initial impact energy of the sphere with the same velocity. When the same position of the tail beam is impacted, the contact force between the rock sphere and the tail beam increases, as well as the energy transferred to the tail beam. Therefore, the vibration amplitude of the tail beam after impact grows while the ratio of the energy of the sphere after impact to its initial impact energy reduces. And the comprehensive recovery coefficient (which is defined as the ratio of the maximum rebound velocity after impact to the initial impact velocity) decreases as the radius of sphere increases.

(5) When the coal and gangue elastic spheres (with the same radius and different materials) impact the same position of the tail beam at the same velocity, the spring stress produced by the impact of coal-rock sphere on the tail beam, the vibration acceleration and velocity of the rigid node of the tail beam, and the acceleration of the rock sphere are much smaller than those of sandstone elastic sphere and the marble elastic sphere. The simulations only take the elastic properties of the sphere into consideration but fail to consider the brittleness of the rock sphere, so the rebound velocity of the coal elastic sphere is much faster than that of sandstone elastic sphere and marble elastic sphere according to the simulation results. In reality, both coal and gangue are brittle objects. In the actual experiment of the gangue impacting the tail beam, they will be damaged and broken among which the coal is easier to break than gangue. In the actual working condition of the coal and gangue impacting the tail beam, the differences of the oil pressure and its variable quantity of the jack of tail beam, the vibration velocity differences of the tail beam after impact, and the rebound velocity differences of the particles after impact will be greater. Based on the differences of these contact responses, it will be more realizable for coal gangue identification.

In this paper, a four-in-one contact-structure impact dynamic model composed by the rock sphere, the tail beam, the jack of the tail beam, and the supporting frame is established by combining the solid contact theory with the structural mechanics of the tail beam. This research provides a theoretical basis for the impact between the particles and the complex support structures and supports a simulation method in finite element software for the contact analysis of the system which contains the hydraulic cylinder. It also proves the feasibility of identifying coal gangue based on the differences of the system contact response after the impact by coal gangue, as well as offers a research basis for the realization of identification technology of the coal gangue in the longwall top coal caving. In the future research, the brittleness of coal gangue particles will be considered. And under this consideration, the system contact response and response differences of the coal gangue impact on the tail beam will be studied.

\section{Data Availability}

The data used to support the findings of this study are included within the article.

\section{Conflicts of Interest}

The authors confirm that this article content has no conflicts of interest.

\section{Authors' Contributions}

Yang Yang completed this research, included the theoretical and simulation modeling, and wrote the paper. Lirong Wan provided suggestions for revising the paper and has the contributed greatly to the revision of the article. Lirong Wan and Yang Yang provided the funding acquisition. Zhengyuan Xin provided help for the application of the simulation software.

\section{Acknowledgments}

This work was supported by the Postgraduate Science and Technology Innovation Project of the Shandong University of Science and Technology (Grant No. SDKDYC190108), National Natural Science Fund of China (Grant Nos. 51674155 and 51974170), Innovative Team Development Project of Ministry of Education (Grant No. IRT_16R45), and National Natural Science Fund of Shandong Province (Grant No. ZR2019MEE067).

\section{References}

[1] "Outline of the Thirteenth Five-Year Plan for National Economic and Social Development of the People's Republic of China," People's Daily, vol. 24723, Beijing, China, 2016.

[2] L. H. Li, "Research progress of automatic recognition of coalgangue mixedness in longwall top-coal caving face," Coal Engineering, vol. 49, no. 10, pp. 30-34, 2017.

[3] Q. X. Qi, Y. S. Pan, L. Y. Shu et al., "Theory and technical framework of prevention and control with different sources in multi-scales for coal and rock dynamic disasters in deep mining of coal mines," Journal of China Coal Society, vol. 43, no. 7, pp. 1801-1810, 2018.

[4] L. J. Xu, Research on key technology of squirrelcage selectivity separation equipment for coal and Gangue underground, Ph.D. thesis, China University of Mining and Technology, Xuzhou, China, 2012.

[5] Y. Yang, Q. L. Zeng, G. J. Yin, and L. R. Wan, "Vibration test of single coal gangue particle directly impacting the metal plate and the study of coal gangue recognition based on vibration signal and stacking integration," IEEE Access, vol. 7, pp. 106784-106805, 2019. 
[6] C. C. Tan, "The research of coal gangue identification and separation technique based on image processing technology," Thesis for the degree of master, Taiyuan University of Technology, Taiyuan, China, 2017.

[7] National Bureau of Statistics, Statistical Bulletin of the People's Republic of China on National Economic and Social Development in 2008, National Bureau of Statistics, Beijing, China, 2009.

[8] National Bureau of Statistics, Statistical Bulletin of the People's Republic of China on National Economic and Social Development in 2009, National Bureau of Statistics, Beijing, China, 2010.

[9] National Bureau of Statistics, Statistical Bulletin of the People's Republic of China on National Economic and Social Development in 2010, National Bureau of Statistics, Beijing, China, 2011.

[10] National Bureau of Statistics, Statistical Bulletin of the People's Republic of China on National Economic and Social Development in 2011, National Bureau of Statistics, Beijing, China, 2012.

[11] National Bureau of Statistics, Statistical Bulletin of the People's Republic of China on National Economic and Social Development in 2012, National Bureau of Statistics, Beijing, China, 2013.

[12] National Bureau of Statistics, Statistical Bulletin of the People's Republic of China on National Economic and Social Development in 2013, National Bureau of Statistics, Beijing, China, 2014.

[13] National Bureau of Statistics, Statistical Bulletin of the People's Republic of China on National Economic and Social Development in 2014, National Bureau of Statistics, Beijing, China, 2015.

[14] National Bureau of Statistics, Statistical Bulletin of the People's Republic of China on National Economic and Social Development in 2015, National Bureau of Statistics, Beijing, China, 2016.

[15] National Bureau of Statistics, Statistical Bulletin of the People's Republic of China on National Economic and Social Development in 2016, National Bureau of Statistics, Beijing, China, 2017.

[16] National Bureau of Statistics, Statistical Bulletin of the People's Republic of China on National Economic and Social Development in 2017, National Bureau of Statistics, Beijing, China, 2018.

[17] National Bureau of Statistics, Statistical Bulletin of the People's Republic of China on National Economic and Social Development in 2018, National Bureau of Statistics, Beijing, China, 2019.

[18] "China industry information," July 2016, http://www.chyxx. com/industry/201612/474936.html.

[19] A. Vakilin and B. K. Hebblewhite, "A new cavability assessment criterion for longwall top coal caving," International Journal of Rock Mechanics and Mining Sciences, vol. 47, no. 8, pp. 1317-1329, 2010.

[20] N. E. Yasitli and B. Unver, "3D numerical modeling of longwall mining with top-coal caving," International Journal of Rock Mechanics and Mining Sciences, vol. 42, no. 2, pp. 219-235, 2005.

[21] J. H. Wang, B. Yu, H. P. Kang et al., "Key technologies and equipment for a fully mechanized top-coal caving operation with a large mining height at ultra-thick coal seams," International Journal of Coal Science and Technology, vol. 2, no. 2, pp. 97-161, 2015.
[22] I. Goktay Ediz, D. W. Dixon-Hardy, H. Akcakoca, and H. Aykul, "Application of retreating and caving longwall (top coal caving) method for coal production at GLE Turkey," Mining Technology, vol. 115, no. 2, pp. 41-48, 2013.

[23] B. Yu, J. Zhao, T. J. Kuang, and X. B. Meng, "In situ investigations into overburden failures of a super-thick coal seam for longwall top coal caving," International Journal of Rock Mechanics and Mining Sciences, vol. 78, pp. 155-162, 2015.

[24] B. Yu, J. Zhao, and H. T. Xiao, "Case study on overburden fracturing during longwall top coal caving using microseismic monitoring," Rock Mechanics and Rock Engineering, vol. 50, no. 2, pp. 507-511, 2017.

[25] W. Z. Cao, J. Q. Shi, G. Y. Si, S. Durucan, and A. Korre, "Numerical modelling of microseismicity associated with longwall coal mining," International Journal of Coal Geology, vol. 193, pp. 30-45, 2018.

[26] H. Basarir, I. F. Oge, and O. Aydin, "Prediction of the stresses around main and tail gates during top coal caving by 3D numerical analysis," International Journal of Rock Mechanics and Mining Sciences, vol. 76, pp. 88-97, 2015.

[27] H. Alehossein and B. A. Poulsen, "Stress analysis of longwall top coal caving," International Journal of Rock Mechanics and Mining Sciences, vol. 47, no. 1, pp. 30-41, 2010.

[28] X. Q. Zhang, P. L. Gong, K. Wang, J. Z. Li, and Y. L. Jiang, "Characteristic and mechanism of roof fracture ahead of the face in an LTCC panel when passing an abandoned roadway: a case study from the Shenghua Coal Mine, China," Rock Mechanics and Rock Engineering, vol. 52, no. 8, pp. 27752788, 2019.

[29] N. B. Zhang, C. Y. Liu, and P. J. Yang, "Flow of top coal and roof rock and loss of top coal in fully mechanized top coal caving mining of extra thick coal seams," Arabian Journal of Geosciences, vol. 9, no. 6, p. 465, 2016.

[30] J. W. Zhang, J. C. Wang, W. J. Wei, Y. Chen, and Z. Y. Song, "Experimental and numerical investigation on coal drawing from thick steep seam with longwall top coal caving mining," Arabian Journal of Geosciences, vol. 11, no. 5, p. 96, 2018.

[31] C. Liu, H. M. Li, and H. Mitri, "Effect of strata conditions on shield pressure and surface subsidence at a longwall top coal caving working face," Rock Mechanics and Rock Engineering, vol. 52, no. 5, pp. 1523-1537, 2019.

[32] M. Khanal, D. Adhikary, and R. Balusu, "Evaluation of mine scale longwall top coal caving parameters using continuum analysis," Mining Science and Technology, vol. 21, no. 6, pp. 787-796, 2011.

[33] G. Y. Si, S. Jamnikar, J. Lazar et al., "Monitoring and modelling of gas dynamics in multi-level longwall top coal caving of ultra-thick coal seams, part I: borehole measurements and a conceptual model for gas emission zones," International Journal of Coal Geology, vol. 144-145, pp. 98-110, 2015.

[34] G. Y. Si, J. Q. Shi, S. Durucan et al., "Monitoring and modelling of gas dynamics in multi-level longwall top coal caving of ultra-thick coal seams, Part II: numerical modelling," International Journal of Coal Geology, vol. 144-145, pp. 58-70, 2015.

[35] M. R. Brake, "An analytical elastic-perfectly plastic contact model," International Journal of Solids and Structures, vol. 49, no. 22, pp. 3129-3141, 2012.

[36] M. R. W. Brake, "An analytical elastic plastic contact model with strain hardening and frictional effects for normal and oblique impacts," International Journal of Solids and Structures, vol. 62, pp. 104-123, 2015. 
[37] H. Minamoto and S. Kawamura, "Moderately high speed impact of two identical spheres," International Journal of Impact Engineering, vol. 38, no. 2-3, pp. 123-129, 2006.

[38] E. Olsson and P. L. Larsson, "The effect of contact conditions and material properties on the elasticity terminus of a spherical contact," Wear, vol. 319, no. 1-2, pp. 110-117, 2006.

[39] T. J. Wang, L. Q. Wang, L. Gu, and D. Z. Zheng, "Stress analysis of elastic coated solids in point contact," Tribology International, vol. 86, pp. 52-61, 2015.

[40] J. Rojek, D. Lumelskyj, S. Nosewicz, and B. RomelczykBaishya, "Numerical and experimental investigation of an elastoplastic contact model for spherical discrete elements," Computational Particle Mechanics, vol. 6, no. 3, pp. 383-392, 2018.

[41] R. L. Jackson, I. Green, and D. B. Marghitu, "Predicting the coefficient of restitution of impacting elastic-perfectly plastic spheres," Nonlinear Dynamics, vol. 60, no. 3, pp. 217-229, 2010.

[42] Y. Yang, Q. L. Zeng, and L. R. Wan, "Dynamic response analysis of the vertical elastic impact of the spherical rock on the metal plate," International Journal of Solids and Structures, vol. 158, pp. 287-302, 2019.

[43] Y. Yang, Q. L. Zeng, and L. R. Wan, "Contact response analysis of vertical impact between elastic sphere and elastic half space," Shock and Vibration, vol. 2018, Article ID 1802174, 15 pages, 2018.

[44] J. Wang, Q. Li, C. W. Yang, and C. Z. Zhou, "Repeated loading model for elastic-plastic contact of geomaterial," Advances in Mechanical Engineering, vol. 10, no. 7, pp. 1-15, 2018.

[45] P. Yan, J. H. Zhang, Q. Fang, and Y. D. Zhang, "Numerical simulation of the effects of falling rock's shape and impact pose on impact force and response of RC slabs," Construction and Building Materials, vol. 160, pp. 497-504, 2018.

[46] L. Skrinjar, J. Slavič, and M. Boltžar, "A review of continuous contact-force models in multibody dynamics," International Journal of Mechanical Sciences, vol. 145, pp. 171-187, 2018.

[47] E. Willert, I. A. Lyashenko, and V. L. Popov, "Influence of the Tabor parameter on the adhesive normal impact of spheres in Maugis-Dugdale approximation," Computational Particle Mechanics, vol. 5, no. 3, pp. 313-318, 2018.

[48] B. Zhao, S. Zhang, and L. M. Keer, "Spherical elastic-plastic contact model for power-law hardening materials under combined normal and tangential loads," Journal of Tribology, vol. 139, no. 2, Article ID 021401, 2017.

[49] Z. H. Wang, P. H. Wang, X. K. Jing, J. Zhou, and C. Z. Xiao, “A study on inter-particle contact behaviors and micro contact models of coarse-grained soil," Chinese Journal of Rock Mechanics and Engineering, vol. 37, no. 8, pp. 1980-1992, 2018.

[50] X. Q. Lu, H. Z. Xu, and B. Zhao, "Effect of hardening exponent of power-law hardening elastic-plastic substrate on contact behaviors in coated asperity contact," Materials, vol. 11, no. 10, p. 1965, 2018.

[51] Y. Yuan, L. H. Zhang, and Y. Q. Xu, "The mechanical model of contact between a sphere-based fractal rough surface and a rigid flat surface," Journal of Xi'an JiaoTong University, vol. 53, no. 5, pp. 176-186, 2019.

[52] X. Wang, Y. X. Xia, and T. Y. Zhou, "Theoretical analysis of rockfall impacts on the soil cushion layer of protective structures," Advances in Civil Engineering, vol. 2018, Article ID 9324956, 2018.

[53] L. C. Liang, J. J. Tian, H. Zheng, and S. J. Jiao, "A study on force transmission in a hydraulic support under impact loading on its canopy beam," Journal of China Coal Society, vol. 40, no. 11, pp. 2522-2527, 2015.
[54] L. R. Wan, P. Liu, Z. S. Meng, and Y. J. Lu, "Analysis of the influence of impact load on shield beam of hydraulic support," Journal of China Coal Society, vol. 42, no. 9, pp. 2462-2467, 2016.

[55] X. K. Liu, Z. H. Zhao, and R. Zhao, "Study on dynamic features of leg applied to hydraulic powered support under bumping load," Coal Science and Technology, vol. 40, no. 12, pp. 66-70, 2012.

[56] K. L. Johnson, Contact Mechanics, Cambridge University Press, Cambridge, UK, 1985.

[57] M. Margarida, M. Pedro, F. Paulo, and M. L. Hamid, "Compliant contact force models in multibody dynamics: evolution of the Hertz contact theory," Mechanism and Machine Theory, vol. 53, pp. 99-121, 2012.

[58] C. Braccesi and L. Landi, "A general elastic-plastic approach to impact analysis for stress state limit evaluation in ball screw bearings return system," International Journal of Impact Engineering, vol. 34, no. 7, pp. 1272-1285, 2007.

[59] S. Krijt, C. Guttler, D. Heißelmann, C. Dominik, and A. G. G. M. Tielens, "Energy dissipation in head-on collisions of spheres," Journal of Physics D: Applied Physics, vol. 46, no. 43, Article ID 435303, 2013.

[60] M. R. Brake, "The effect of the contact model on the impactvibration response of continuous and discrete systems," Journal of Sound and Vibration, vol. 332, no. 15, pp. 38493878, 2013.

[61] M. L. Hamid and N. Parviz, "Continuous contact force models for impact analysis in multibody systems," Nonlinear Dynamics, vol. 5, pp. 193-207, 1994.

[62] M. L. Hamid and N. Parviz, "A contact force model with hysteresis damping for impact analysis of multibody system," Journal of Mechanical Design, vol. 112, pp. 369-376, 1990.

[63] P. Flores, C. S. Koshy, H. M. Lankarani, J. Ambrósio, and J. C. P. Claro, "Numerical and experimental investigation on multibody systems with revolute clearance joints," Nonlinear Dynamics, vol. 65, no. 4, pp. 383-398, 2011.

[64] M. Megahed and A. F. Haroun, "Analysis of the dynamic behavioral performance of mechanical systems with multiclearance joints," Journal of Computational and Nonlinear Dynamics, vol. 7, no. 1, Article ID 011002, 2012.

[65] F. Paulo, "A parametric study on the dynamic response of planar multibody systems with multiple clearance joints," Nonlinear Dynamics, vol. 61, no. 4, pp. 633-653, 2010.

[66] F. Paulo, M. Margarida, S. Miguel, and M. Jorge, "On the continuous contact force models for soft materials in multibody dynamics," Multibody System Dynamics, vol. 25, no. 3, pp. 257-375, 2011.

[67] K. Chen, G. J. Zhang, R. Wu, L. Wang, H. M. Zheng, and S. H. Chen, "Dynamic analysis of a planar hydraulic rockbreaker mechanism with multiple clearance joints," Shock and Vibration, vol. 2019, Article ID 4718456, 17 pages, 2019. 


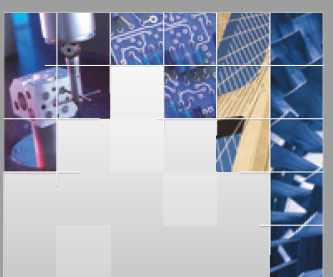

\section{Enfincering}
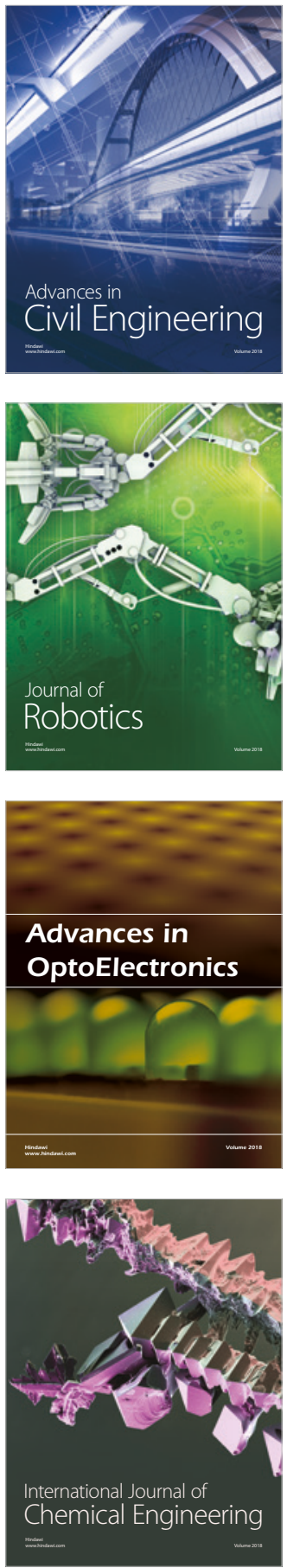

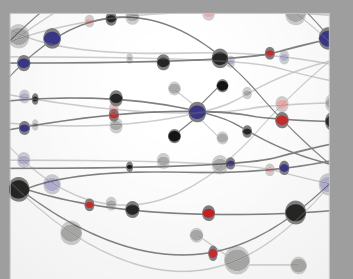

\section{Rotating \\ Machinery}

The Scientific World Journal

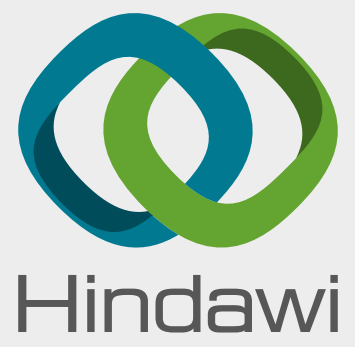

Submit your manuscripts at

www.hindawi.com
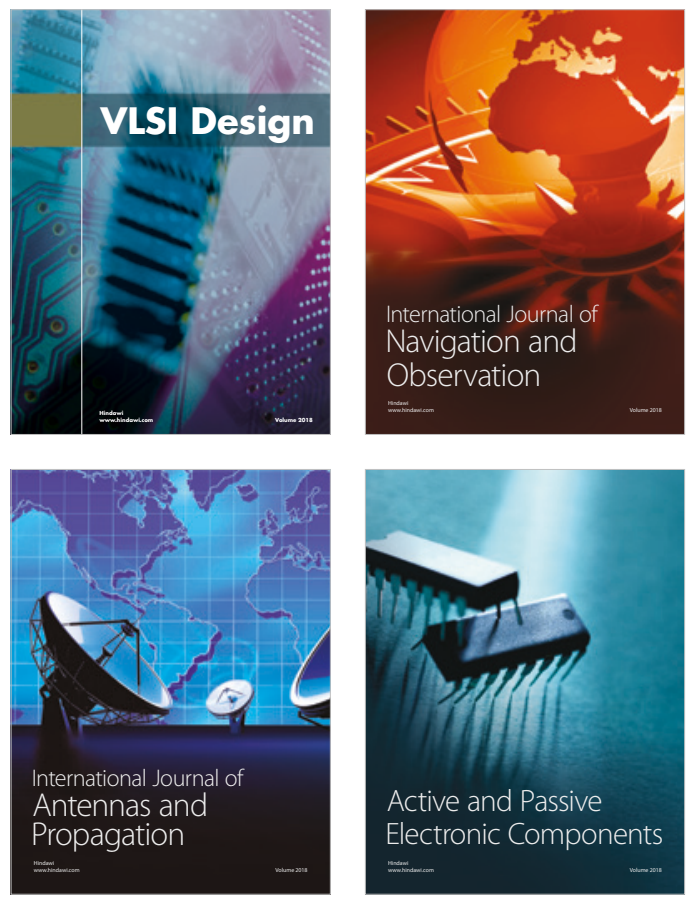
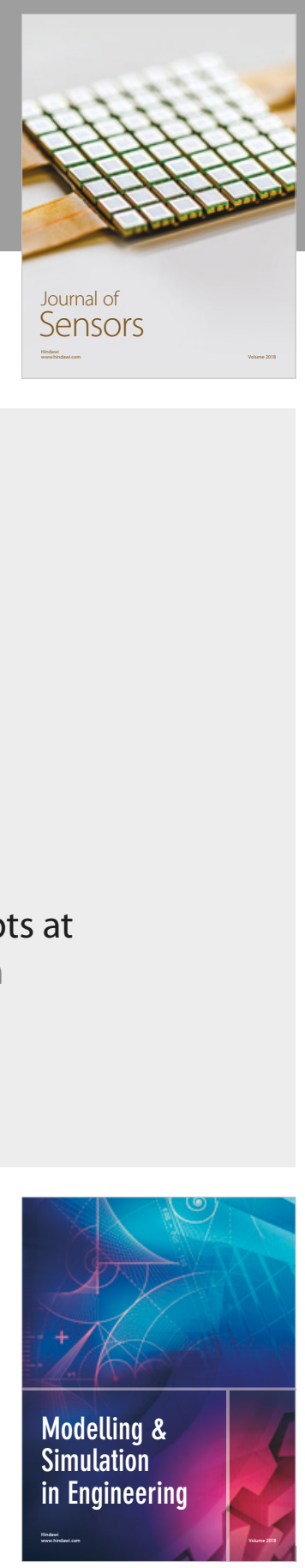

\section{Advances \\ Multimedia}
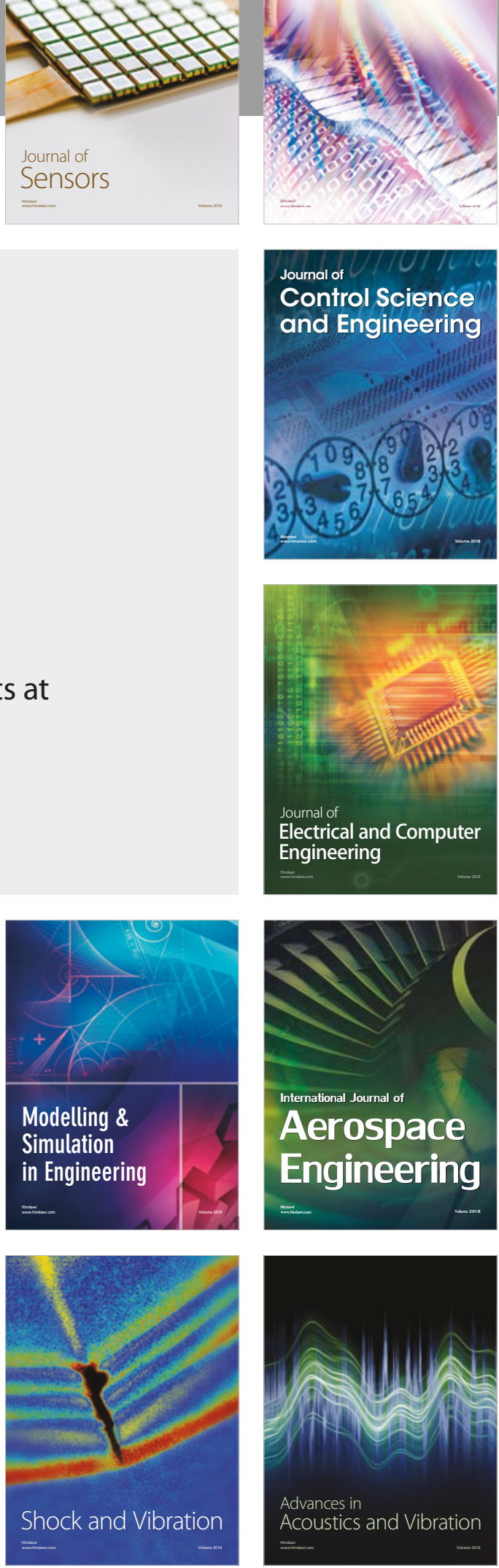